\title{
Pricing Strategy and Technology Choices: An Empirical Investigation of "Everyday Low Price" in the Domestic US Airline Sector
}

\author{
Raymond G. Sin \\ School of Business and Management \\ Hong Kong University of Science and \\ Technology \\ Clear Water Bay, Hong Kong \\ rsin@ust.hk
}

\author{
Ramnath K. Chellappa \\ Goizueta Business School, Emory University \\ Atlanta, GA 30322-2710 \\ ram@bus.emory.edu
}

\author{
S. Siddarth \\ Marshall School of Business, University of Southern California \\ Los Angeles, CA 90089 \\ siddarth@usc.edu
}

\begin{abstract}
There is a rich literature in economics on factors that govern airline prices. With approximately $50 \%$ of airline tickets sold online, there is now a renewed interest in investigating airline pricing particularly amongst Information Systems (IS) researchers. While market transparency created by online travel agents (OTAs) is a motivation enough to re-examine airline pricing, one missing piece calls for a thorough empirical investigation: In all extant studies (economics, marketing and IS), pricing by two major airlines, Southwest and JetBlue, has been ignored. Of particular interest to IS researchers is the fact that these two airlines practice a unique form of pricing called Everyday Low Price (EDLP) and have made certain technology-related choices that are distinct and different from previously studied carriers.

We test extant theories of price discrimination in the new online context with both posted and transacted prices, including those of the two EDLP airlines. We find that the EDLP airlines demonstrate distinctly different pricing choices - they are very particular about maintaining price consistency, while except in the case of advance purchase, they forgo other conventional opportunities to price discriminate. They also aggressively undercut competition when equipped with certain cost advantages. Further empirical investigation reveals why EDLP airlines forgo participation in OTAs that potentially offer a larger market. In particular, while promising a larger marketplace, OTAs have the ability to reveal the lowest prices in the market; we find that EDLP prices are lowest in the market only $26 \%$ of the time - in other words, consumers have $70 \%$ chances of obtaining a better deal from other "non-low price" airlines for any given ticket. We also show that EDLP prices, though not necessarily being the lowest in the market, do tend towards the lower end of the market spectrum.
\end{abstract}

Keywords: Information technology, everyday low price (EDLP), airlines, pricing, hierarchical linear model 


\section{Introduction}

Many organizations are faced with the daunting task of revisiting/realigning their business strategies with technological changes, perhaps more so in some industries than in others. One industry that has been fundamentally altered by technology is the airline sector, where computerized reservation systems (CRSs - later integrated and globalized, known as the "Global Distribution Systems" or GDSs) have shaped airline operations from pricing to crew scheduling. Extant research suggests that the U.S. domestic airlines have seized the opportunities created by these technological innovations, and enjoyed proven gains in organizational efficiency and economic benefits (Banker and Johnston 1993; Duliba et al. 2001). Similarly, the advent of the Internet and the various online travel agents (OTAs) saw the airlines rushing to participate in Orbitz, Expedia and Travelocity owing to a marketplace that promised to be larger than that offered by brick-n-mortar travel agencies and the airlines' own Web presence. The competitive landscape of the U.S. domestic airline sector has always been of great interest to economists and regulators alike, and more recently in information systems as well, thus providing us with a rich literature base (Borenstein 1989; Chellappa et al. 2011). However, almost all existing research on airline pricing, including the large body of airline literature in economics, has failed to include in their analyses the pricing strategy of industry giant Southwest Airlines (an airline that has been operational since the seventies) and later entrant JetBlue Airways. Southwest and JetBlue stand out from the rest of their competitors not only in terms of their ability to remain profitable but also in their steady expansion. In particular, Southwest's market share has increased by nearly 50\% between 2004 and 2010, ranking as the second largest airline whose dominance is only marginally behind Delta (even after Delta has merged with Northwest in early 2010), while JetBlue's share has more than doubled during the same period when all other major carriers are confronted with major setback (see Figure 1 and Table 1 for detail). Today, the combined share of Southwest and JetBlue is approaching $20 \%$ in the domestic air travel market.

Apart from the fact that the strategies of these two airlines have not been empirically examined, both Southwest and JetBlue are of particular interest to IS researchers for two reasons. First, they appear to deviate from much of the airline industry's conventional adoption of technology; specifically, Southwest and JetBlue have been reluctant participants in the GDSs and have opted out of offering their fares through OTAs. Second, they pursue a pricing 
strategy through an Everyday Low Price (EDLP) format, as opposed to most others who pursue promotional pricing with frequent promotions and deals (known as the PROMO or HILO format), which is hitherto unobserved in the airline industry. A main goal of our paper is to reconcile the firms' technological choices and their pricing strategy. Along the lines of an emerging stream of IS literature that underscores the relationship between technology and price/product/market transparency (Granados et al. 2008; Granados et al. 2010), we empirically examine specific pricing-related choices made by the EDLP airlines vis-à-vis their competitors. Another unique aspect of our research is the examination of both offered and transacted prices, which allows us to empirically verify whether firm-intended prices indeed clear in the marketplace.

Figure 1: Airline Market Share

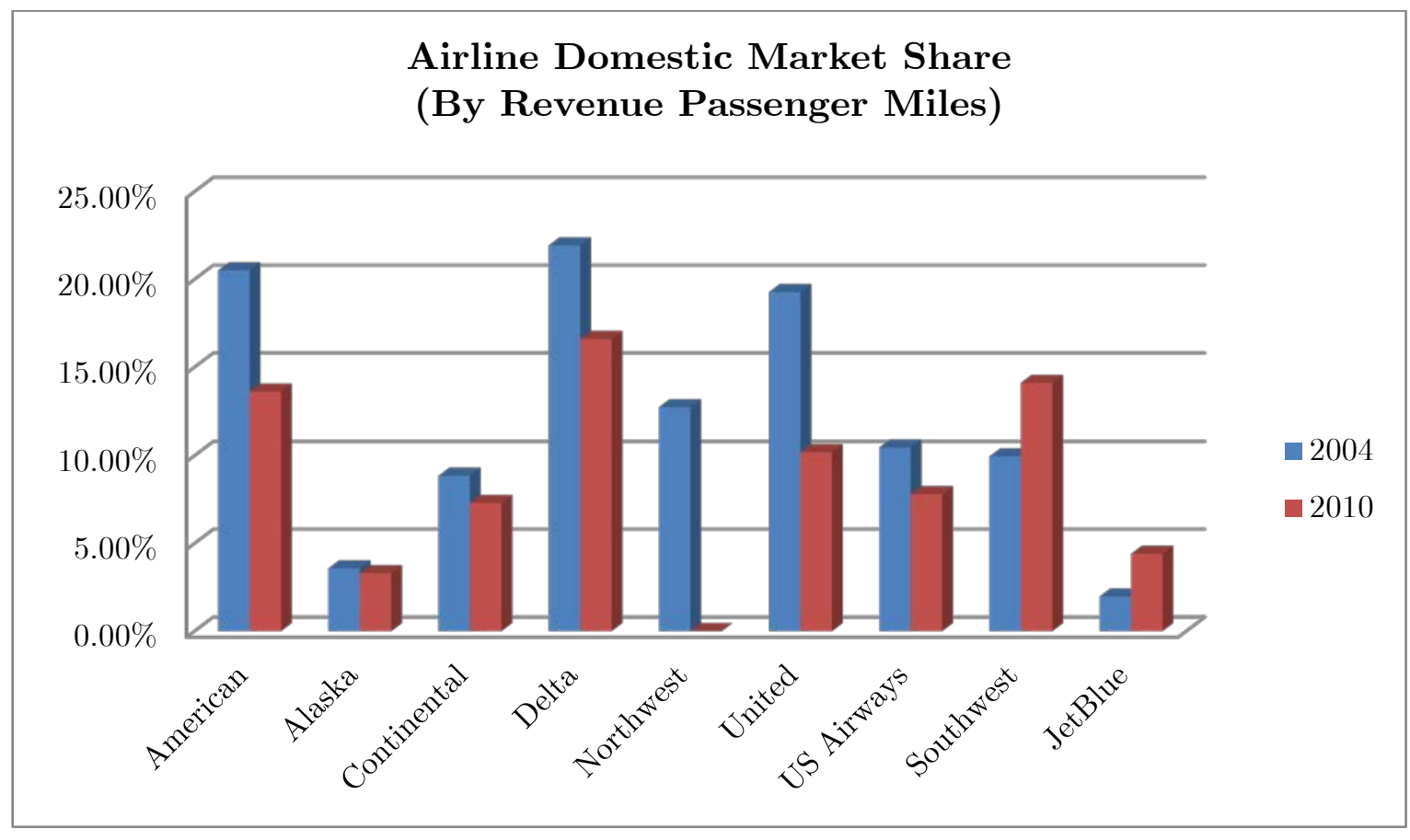

Table 1: Revenue Share by Airline, 2004 vs. 2010

\begin{tabular}{|l|r|r|}
\hline \multirow{2}{*}{ Airline } & \multicolumn{2}{c|}{ Year } \\
\cline { 2 - 3 } & \multicolumn{1}{|c|}{2004} & \multicolumn{1}{c|}{2010} \\
\hline American & $20.51 \%$ & $13.60 \%$ \\
\hline Alaska & $3.57 \%$ & $3.30 \%$ \\
\hline
\end{tabular}




\begin{tabular}{|l|r|c|}
\hline Continental & $8.85 \%$ & $7.30 \%$ \\
\hline Delta & $21.93 \%$ & $16.60 \%$ \\
\hline Northwest $^{1}$ & $12.71 \%$ & -- \\
\hline United & $19.27 \%$ & $10.20 \%$ \\
\hline US Airways & $10.46 \%$ & $7.80 \%$ \\
\hline Southwest & $9.95 \%$ & $14.10 \%$ \\
\hline JetBlue & $1.97 \%$ & $4.40 \%$ \\
\hline
\end{tabular}

Source: Bureau of Transportation Statistics

Our research is informed by theories and findings from three distinct literature streams: airline pricing from economics (Borenstein 1989; Borenstein 1991; Berry et al. 1997; Hayes and Ross 1998), price formats and pricing strategies from marketing (Hoch et al. 1994; Bell and Lattin 1998; Shankar and Bolton 2004) and a burgeoning literature on airline pricing in online markets (Clemons et al. 2002; Chellappa, Sin et al. 2011). It is salient to note that extant research in economics, while not accounting for pricing strategy of Southwest and JetBlue, provides us with an array of factors that affect airline pricing. There is clear evidence that the non-EDLP airlines employ various segmentation strategies for the purpose of price discrimination; for example, ticket prices are higher closer to departure and serves as means to extract opportunity costs from consumers who have higher willingness to pay (Gale and Holmes 1993; Dana 1998; Stavins 2001; Clemons, Hann et al. 2002). Similarly, Saturday night stay-over restriction is often used as a way to discriminate between the business and leisure travelers (Stavins 2001). While it could be expected that EDLP airlines will also engage in comparable segmentation, marketing literature suggests that the EDLP format requires low and consistent prices (Hoch, Dreze et al. 1994; Ho et al. 1998). Thus these firms are faced with a natural tension between their choice of strategy and the advantages provided by price discrimination.

Additional tensions arise when these airlines are confronted with technological developments. Southwest and JetBlue's promulgation of EDLP does not necessarily benefit from technologies like the GDS - while simple advantages of computerization of ticketing is to be availed, the much hailed lowered menu cost is useful only if frequent price changes are in the

\footnotetext{
${ }^{1}$ Northwest Airlines has merged with and operated under Delta Air Lines since January 31, 2010.
} 
offing. Furthermore, the long established Southwest Airlines had always eschewed intermediaries well before the advent of the Internet by selling tickets through the phone, at the airport or at their regional offices. In the post-Internet era, these two airlines appear not to be enticed by the promise of a larger marketplace offered by OTAs but rather sell tickets directly through their own Web sites. This technology-related choice requires further investigation in that if these are indeed everyday "low price" airlines, they should benefit from price transparency offered the OTAs. Thus in this research we shall empirically investigate the specific strategic choices made by these airlines vis-à-vis their online prices.

As a first step, we decompose a firm's pricing strategy into two dimensions, namely price consistency and price magnitude. The former captures the frequency of promotions in tickets for the HILO airlines and is a measure of the "everyday" aspect of their EDLP counterparts, while the latter allows us to examine the "low price" element of the pricing strategy. We then develop and estimate a hierarchical model that accounts for partial dependence among prices due to market- and airline-specific factors, using pricing data for over 200,000 tickets offered online by the 14 largest carriers in 268 U.S. domestic air travel markets. In constructing this model, we carefully control for potential endogeneity that may arise from market share-related measures. Further, since our model incorporates a number of dichotomous variables at various levels (e.g. advance purchase and Saturday stay-over, hub operation, route distance), we exercised extreme caution in interpreting related effects and drawing inferences from our statistical analysis. We also repeat all of our analyses with the transacted price data from DB1B (a 10\% sample of all tickets sold by reporting carriers, provided by the Bureau of Transportation Statistics) both as a robustness check of our original results and as a means to verify the extent to which the pricing strategies of airlines are absorbed by the market. While existing research typically investigates either offered prices or transacted prices, our work examines firm-specific strategies (and hence the respective price setting behaviors) and conclude with similar examination of prices at which tickets have actually been purchased.

The remainder of the paper is organized as follows. Section 2 presents the theoretical framework for our analysis. Section 3 discusses the data and empirical method employed in this study, which is followed by a discussion of results in Section 4 . Section 5 concludes with implications and directions for future research. 


\section{Airline pricing: Conceptual development}

Pricing of airline tickets is a rather complex process, where an airline not only has to consider its costs of operation but also demand-side characteristics and the competitive landscape involving multiple competitors. Extant literature has identified a number of price co-variates in the airline sector, which fall largely into the following categories: 1. Ticket category; which refers to the use of ticket restrictions to differentiate between business and leisure travelers, such as advance purchase and Saturday stay-over requirements (Gale and Holmes 1993; Dana 1998; Stavins 2001; Clemons, Hann et al. 2002). 2. Airline and market characteristics; such as nonstop distance between the endpoint airports, market share and the corresponding Herfindahl Index (Borenstein 1989; Borenstein 1991; Borenstein and Rose 1994; Berry, Carnall et al. 1997; Hayes and Ross 1998). 3. Cost and operational structures; such as aircraft size, direct cost measure (cost per available seat-mile), flight frequency and hub-operations (Borenstein 1989; Stavins 2001).

There is, however, one key missing aspect in extant research on airline pricing - it does not account for a firm's choice of its overall or portfolio-level pricing strategy. In this regard, the marketing literature suggests that firms employ various price formats to instill a certain price image in the minds of the consumers. Price formats generally exist on a continuum where the extremes are "everyday low price" (EDLP) and the promotional (HILO) formats. Firms strategically place themselves on this continuum so as to be attractive to different consumer segments. The HILO format incentivizes consumers to shop with the firm by frequently offering promotions and temporal price discounts (Lal and Rao 1997; Bell and Lattin 1998). The EDLP format, on the other hand, appeals to consumers less prone to searching, i.e. these firms aim to create a low-price image by maintaining relatively consistent prices and offering on-an-average low prices. Extant literature has identified Southwest as a practitioner of this strategy, though little is known about what EDLP means in the airline industry (Hoch, Dreze et al. 1994; Chellappa, Sin et al. 2011). However, there is currently little or no understanding of how these airlines execute their pricing strategy, e.g., if they will follow similar rules of price-discrimination as other major carriers. Further, there is also no prior work that explains why these airlines have made these other technology choices, e.g., not participating in online travel agencies such as Orbitz, Expedia, etc. 


\subsection{Consumer segments and price discrimination in the airline sector}

Economic theory posits that, whenever possible, firms would pursue some form of discrimination to extract consumer surplus. While information asymmetry (the lack of full knowledge of their customers' willingness to pay) and competition prevents them from full-on complete discrimination (Png 2001), the airline industry has identified a number of traveler attributes along which firms engage in indirect segmentation.

Airline tickets are unique in that they are a perishable commodity; i.e. if a seat is not occupied then the firm gets zero revenue from it with no opportunities of secondary/used markets. When one considers such perishable commodities in daily products such as flowers or produce, grocers typically offer discounts on products that are approaching the end of their life to salvage the residual values before they become unfit for consumption. On the other hand, prices of airline tickets generally increase as the departure date approaches, so that consumers with a higher opportunity cost of time are charged higher prices (Dana 1998; Stavins 2001). Similarly, tickets that include a Saturday night stay-over are typically cheaper than those without this requirement. The general rationale is that business travelers place higher values on flexibility and are reluctant to spend the weekend away from home, while leisure travelers will be willing to bear some inconvenience, such as purchasing tickets well in advance and staying for the weekend, for a cheaper price. By artificially differentiating the otherwise identical products, airlines can price tickets differently to target different consumer segments based on their relative opportunity costs (Gale and Holmes 1993; Dana 1998; Stavins 2001; Clemons, Hann et al. 2002). Note that while there is currently no analysis on the role of Saturdayrestriction in airlines' Internet prices, we have no a priori reason to believe that extant airlines would employ such segmentation differently. Hence we expect ticket prices offered by the major carriers to exhibit evidence of discrimination along this dimension even in the online

environment, though what remains unknown is whether the EDLP carriers will also discriminate along the same dimensions.

\subsection{Consumer segments and everyday low price}

There has been no prior research that examines whether EDLP airlines will also price discriminate along the natural consumer segments that exist in the air travel market, because doing so implies implementing price changes that may detract from their price image. One could argue that discriminating on the basis of advance purchase poses relatively lower risks to 
these airlines, as it requires consumers to keep track of price changes across a large number of offers over time in order to detect such a discrimination practice. On the other hand, the "Saturday night stay" rule is an artifact invented by yield managers who, after adopting the CRS technology, discovered that business travelers have strong preferences of returning home for the weekend (Associates 2002). While the Saturday restriction has become a key marketing tactic employed by non-EDLP airlines to attain higher profits through effectively segmenting business travelers from leisure ones, EDLP carriers may refrain from employing such segmentation as it requires them to discriminate business passengers even within a given particular advance purchase period, which is easily observable by the consumers. In fact, there is anecdotal evidence that Southwest and JetBlue both disregard Saturday-restriction as means of product differentiation; not only do both airlines emphasize a fixed one-way fare for a sizable number of origin-destination pairs in their marketing messages, but their "round-trip" ticket is also simply a composition of two one-way tickets. For example, the cheapest round-trip fare between Los Angele and San Francisco on Southwest with two-week advance purchase is $\$ 108-$ a combination of the fares for two one-way tickets (LAX-SFO, at \$49; plus SFO-LAX, at \$59); the price does not change with regards to whether the return trip is on weekday or weekend. Indeed, by removing the return option, their price simply reduces to the one-way fare from Los Angeles to San Francisco, which is $\$ 49$. Given the lack of empirical understanding of the pricing practice of Southwest and JetBlue, whether and how they may practice discrimination along the various consumer segments remain to be investigated.

\subsection{Operational advantages and pricing in the airline sector}

The operations side of the airline industry, such as in the form of hub-presence on a route, can have a significant impact on prices since it can indirectly create both cost and operational advantages for firms (Borenstein 1989). For example, a hub-and-spoke system allows for more efficient use of aircrafts, and can provide additional values to consumers through greater flight frequency and easier connections. Though airlines may enjoy cost savings from hub operations due to economies of scale, prior research shows that these savings may not necessarily be passed on to consumers; because through their control over scarce resources such as gates and runways at hub airports, airlines can deliver greater values and convenience to travelers and command a premium (Borenstein 1989; Berry, Carnall et al. 1997). On the other 
hand, some studies find evidence that airlines lower prices in hub markets to create barriers to entry (Borenstein and Rose 1994; Hayes and Ross 1998; Stavins 2001). While empirical observations on the pricing effects of hub operation are mixed, the general conceptual understanding in this literature favors the premium-based view.

Airplanes vary both in sizes and types; a firm's choice of equipment is intrinsically connected with the geographical distances of routes in which it operates. Extant literature suggests that while larger aircrafts have lower per-seat-mile cost on flights of more than 500 miles, smaller aircrafts are more fuel efficient on short-haul routes. (Borenstein 1989; Berry 1990; Hayes and Ross 1998; Stavins 2001). On long-haul routes, such as from New York (JFK) to West Palm Beach in Florida (PBI), the average plane size of non-EDLP carriers is 182; with a significant variation in both types and sizes of equipments - Delta Airlines operates the 4 different types of planes ranging from 120 to 252 seats, while US Airways operates the 3 with ranging from 120 to 150 seats $^{2}$. On short-haul routes, such as from Boston (BOS) to New York (LGA), the average plane size of non-EDLP carriers is 121 (number of passenger seats); where Delta and US Airways both operate only two types of aircrafts with ranging from 120 to 150 seats.

In summary, non-EDLP airlines operate many different aircrafts to cater to the demands in different markets. While operating different types of aircrafts to cater to the market demand and flight distance on specific routes may allow these airlines to more efficiently utilize their physical assets, the costs associated with maintaining equipment and complications in crew scheduling may outweigh the benefits of doing so. Further, extant research has provided us little understanding of the specific operational details of EDLP airlines, and how these choices may impact their pricing.

\subsection{Operational advantages and everyday low price}

While Southwest and JetBlue do not follow the traditional hub-and-spoke system and focus mainly on point-to-point operations (Morrison 2001), they do maintain hub-like operations

\footnotetext{
${ }^{2}$ The four types of aircrafts operated by Delta are: Boeing 737-800, Boeing 737-300, Boeing 757-200, and Boeing 767-300/300er; the ones operated by US Airways are: Boeing 737-300, Airbus A320-100/200, and Airbus A319. Source: Form 41, Schedules T100 and T100(f) Air Carrier Data (BTS).
} 
and route their flights through certain airports; which are often referred to as their "bases", "focus cities", or simply "busiest airports". Nonetheless, based on definition employed in extant literature (a hub is where an airline has strong presence, along with outbound flights to a large number of destinations) and for the sake of empirical consistency, we consider such airports as their hubs. The major hubs for Southwest are Dallas Love Field (DAL), Chicago Midway (MDW), Baltimore/Washington International (BWI), Houston (HOU), Las Vegas (LAS), and Phoenix Sky Harbor (PHX); while those for JetBlue are Boston (BOS), Fort Lauderdale (FLL), Long Beach (LGB), and New York John F. Kennedy (JFK), Orlando (MCO), and Washington Dulles (IAD). Southwest and JetBlue can potentially benefit from control over resources at these airports, and therefore face a unique dilemma: on one hand, by offering easy connections and more frequent flights through their hub airports, they can leverage these advantages from hub airports to command a premium on the corresponding routes; on the other, charging higher prices on these routes implies creating greater variance in prices, and may hurt their very fundamental pursuit of a low and consistent price image.

Further, as discussed in the previous subsection, an airline's choice of aircrafts is closely related to their choice of markets/routes in which they operate. Interestingly, both EDLP airlines in the domestic U.S. market tend to operate mid-size planes that are most fuel efficient for traveling non-stop distances of less than 500 miles. For example, Southwest operates only Boeing 737 flights with sizes ranging from 122 to 137 seats; while JetBlue operates two types of flights: the Airbus A320 with 156 seats, and the EMBRAER 190 with 100 seats $^{3}$. Compared to their non-EDLP counterparts, Southwest and JetBlue able to enjoy significant cost advantage on short-haul routes from flying smaller planes. Further, not only are their recurring costs of equipment maintenance lower, but they also benefit from improved efficiency of aircraft turnaround operation (i.e. the preparation works that need to be carried out for an inbound aircraft that is scheduled for a following outbound flight). Once again, the EDLP airlines face a unique dilemma: should they keep prices consistent across markets regardless of whether the routes are short-/long-haul? Or should they pass on the cost savings to their consumers to undercut their competitors and create barrier to entry?

${ }^{3}$ At the time of our data collection, JetBlue had not yet introduced the EMBRARER and was only operating the A320. 
Therefore, while there is significant understanding on the usage of operational elements in pricing by airlines such as American, Delta, etc., little is known with regards to how such elements may affect the pricing strategy of Southwest and JetBlue. Since their operations are more hub-like rather than true hub-n-spoke, this particular dimension is perhaps less relevant in their consideration on price discrimination. On the other hand, given the types of aircrafts operated by the EDLP carriers are much more suited for short-haul flights, these airlines might undercut their competitors in short-haul markets where they enjoy substantial cost advantages. In sum, a thorough empirical investigation that incorporates these operational aspects into understanding airline's pricing strategy is warranted.

\subsection{Technology and price transparency in the airline industry}

The first set of technology to arrive in the airline industry was the CRSs (Duliba, Kauffman et al. 2001). Beginning with Sabre created by American Airlines, there are currently four major consolidated Global Distribution Systems (GDSs) including the Amadeus, which captures nearly half of U.S. domestic market share. While the primary purpose of these systems was to reduce distribution costs (one of the airlines' top controllable expenses) and improve internal operating efficiency through automation (Banker and Johnston 1995; Duliba, Kauffman et al. 2001), gradually they evolved into decision tools for strategic purposes. Not only were such systems used to bias travel agents, but they were also helpful for forecasting and crew scheduling on the supply-side. In fact, many other strategic bases for pricing and fare promotions have essentially emerged from these sophisticated systems due to their ability to account for routings, stop-overs, advance purchases, length of stay and a myriad of other factors. Coupled with significantly reducing menu costs, these systems allow airlines to derive and implement a complex mix of pricing strategies. The very restriction on Saturday stay-over itself was indeed identified from this treasure-trove of information, as airlines figured that business travelers were very resistant to spending the weekend away from home (Associates 2002).

While these technologies originated as independent reservation systems carrying only the owner airline's tickets, they later became networked central reservation systems with the ability to act as a clearing house if other airlines participated/provided access to their own reservation systems. The airlines considered in extant research have all adopted one or more of these systems and have their tickets offered through them. Since the Congress introduced regulations 
in mid-80s that required GDSs owners to share sales information and prohibited any kind of information- or fee-based discriminations against competitors, participating airlines have had complete and accurate price and product information on each other's offers (Granados et al. 2006). In essence, GDSs have become a highly transparent trading platform in terms of both price and product information. The advent of the Internet and OTAs have brought forth such transparencies to the general public through aggregating, filtering and simplifying complex information from the GDSs and presenting it in a user-friendly interface. While on one hand increased market transparency can potentially lead to increased price competition, on the other it may facilitate tacit collusion as competing firms can both signal price increases and deter each other from deviating from a tacitly agreed market price through punitive price response (Campbell et al. 2005; Granados, Gupta et al. 2010). In fact, a few recent studies confirm the existence of tacit collusion among non-EDLP airlines, and observe higher prices in markets where these airlines extensively overlap with each other (Evans and Kessides 1994; Gimeno and Jeong 2001). Together with the added advantage of being able to reach a larger customer base, offering tickets through the OTAs appears a natural extension of the technology choice for these airlines.

\subsection{Technology and price transparency: implications to EDLP airlines}

Automation, and the efficiency that comes along with reservation systems, is certainly of benefit and a competitive necessity to all firms; EDLP and otherwise. However, if consistency in fares is truly an objective of EDLP firms, then perhaps the lowered menu cost aspect is not as attractive to them as it is to their promotion-driven counterparts. Beyond complex fare management, GDSs are also important for making one's ticket amenable to part of other bundles, e.g., for travel agencies that put together tour packages that include hotels, cars, etc. To that extant it may be beneficial for these two airlines to also become part of the GDSs.

Participation in OTAs brings one key advantage to the airlines - increased market size and reach to potential customers. Also, since many travelers consult the OTAs, there is a potential for customers themselves to bundle hotel, car, etc. (at the GDS level only the agents have the ability to do such bundling). However, GDSs and OTAs, which are essentially Web front-ends to GDSs, are also platform that makes fares transparent for comparison. In these regards, the pros and cons of being "transparent" in the market (i.e. from joining the OTAs) for the EDLP airlines is not fully understood. Research points out that firms need to trade-off 
between enjoying informational advantage through biased and opaque mechanisms and increased revenues from transparent mechanism (Granados, Gupta et al. 2006); this is a particular concern for EDLP airlines because a basic premise for the success of their strategy hinges on information asymmetry - i.e. not all consumers are aware of all prices in the market. Therefore, EDLP airlines need to weigh their decision to participate in OTAs on the benefits of attracting buyers through a more transparent market versus the losses associated with releasing private information that is visible not only to consumers but also to their competitors (Granados, Gupta et al. 2010). While higher price transparency may facilitate tacit collusion, the prospect of setting higher prices through tacit agreements with competitors may not be relevant to EDLP airlines as it implies detraction from their price image. On the other hand, if Southwest's and JetBlue's fares are indeed low as advertised, then participating should be a win-win for them. While a cursory look at fares offered by the OTAs suggest otherwise, it is important to conduct a thorough empirical examination to fully understand any choice in this regard.

Table 2 summarizes the set of variables that are included in our empirical models. These variables correspond to the various segmentations, market types, and operational differences among airlines that have been discussed in this section. 
Table 2: Description of Variables

\begin{tabular}{|c|c|c|c|}
\hline Factor & Variable & Related Literature & Operationalization \\
\hline $\begin{array}{l}\text { Consumer } \\
\text { Segmentation }\end{array}$ & $\begin{array}{l}\text { Saturday night stay- } \\
\text { over requirement } \\
(B U S) \\
\text { Advance purchase } \\
\text { period } \\
(D D 7, D D 14, D D 21)\end{array}$ & $\begin{array}{l}\text { (Gale and Holmes 1993; } \\
\text { Dana 1998; Stavins 2001; } \\
\text { Clemons, Hann et al. 2002) }\end{array}$ & $\begin{array}{l}B U S=1 \text { if the observed ticket does not include a Saturday night stay- } \\
\text { over requirement; } 0 \text { otherwise. } \\
D D 7=1 \text { if the observed ticket is generated within } 0-7 \text { days of } \\
\text { departure date; } 0 \text { otherwise. } \\
D D 14=1 \text { if the observed ticket is generated within } 7-14 \text { days of } \\
\text { departure date; } 0 \text { otherwise. } \\
D D 21=1 \text { if the observed ticket is generated within } 14-21 \text { days of } \\
\text { departure date; } 0 \text { otherwise. }\end{array}$ \\
\hline \multirow{3}{*}{$\begin{array}{l}\text { Airline/ } \\
\text { Market } \\
\text { Characteristics }\end{array}$} & $\begin{array}{l}\text { Flight distance } \\
(\text { shorthaul })\end{array}$ & $\begin{array}{l}\text { (Borenstein 1989; Berry, } \\
\text { Carnall et al. 1997; Hayes } \\
\text { and Ross 1998; Stavins } \\
\text { 2001) }\end{array}$ & $\begin{array}{l}\text { shorthaul }=1 \text { if the non-stop distance between the origin and the } \\
\text { destination airports on the observed route is equal to or less than } 500 \\
\text { miles; } 0 \text { otherwise. }\end{array}$ \\
\hline & $\begin{array}{l}\text { Market share } \\
\text { (RTshare) }\end{array}$ & $\begin{array}{l}\text { (Borenstein 1989; } \\
\text { Borenstein and Rose 1994) }\end{array}$ & $\begin{array}{l}R T \text { share: the observed carrier's share of passengers on the observed } \\
\text { route. }\end{array}$ \\
\hline & $\begin{array}{l}\text { Herfindahl index } \\
\text { (RTherf) }\end{array}$ & $\begin{array}{l}\text { (Borenstein 1989; } \\
\text { Borenstein and Rose 1994) }\end{array}$ & RTherf is the Herfindahl index for all passengers on the observed route. \\
\hline \multirow{4}{*}{$\begin{array}{l}\text { Operational/ } \\
\text { Cost Structure }\end{array}$} & $\begin{array}{l}\text { Cost per available } \\
\text { seat-mile }(C A S M)\end{array}$ & (Borenstein 1989) & $\begin{array}{l}C A S M \text { : the cost per available seat-mile (in cents) of the observed } \\
\text { airline. }\end{array}$ \\
\hline & $\begin{array}{l}\text { Aircraft size } \\
(\text { EQUIPsize })\end{array}$ & (Borenstein 1989) & $\begin{array}{l}\text { EQUIPsize: the average size of the aircrafts operated by the observed } \\
\text { airline on a given route. }\end{array}$ \\
\hline & $\begin{array}{l}\text { Flight frequency } \\
(\text { freq })\end{array}$ & $\begin{array}{l}\text { (Borenstein and Rose 1994; } \\
\text { Hayes and Ross 1998) }\end{array}$ & $\begin{array}{l}\text { freq : the observed carrier's weekly average number of flights scheduled } \\
\text { for departure from the origin to the destination on a given route. }\end{array}$ \\
\hline & Hub airport $(h u b)$ & $\begin{array}{l}\text { (Borenstein 1989; } \\
\text { Borenstein 1991; Berry, } \\
\text { Carnall et al. 1997; Hayes } \\
\text { and Ross 1998) }\end{array}$ & $\begin{array}{l}h u b=1 \text { if the origin and/or destination airport(s) in a given route is } \\
\text { (are) a hub(s) for the observed airline; } 0 \text { otherwise. }\end{array}$ \\
\hline Price-format & $E D L P$ & New variable & $\begin{array}{l}E D L P=1 \text { if the ticket is offered by an EDLP airline (Southwest or } \\
\text { JetBlue); } 0 \text { otherwise. }\end{array}$ \\
\hline
\end{tabular}




\section{Data and Method}

\subsection{Data}

Our data is collected from two primary sources. First, we obtained prices and detailed descriptions of airline tickets from online travel agents and individual airlines' websites in the third quarter of 2004. This raw data was gathered using web-based spiders that we developed using Curl, and later processed by a parser using Perl and other database scripting languages. In addition to the set of fourteen major U.S. carriers ${ }^{4}$ and three online travel agents (Orbitz, Travelociy, and Expedia), a list of the top 500 U.S. domestic routes was provided as input to the spiders. These markets represent over $86 \%$ of total domestic passenger enplanements (i.e. total number of travelers transported by air within the 50 states) in the U.S. as of 2004 . The spiders were sent out on a daily basis to collect prices and other attributes of tickets requiring one- to four-week advance purchases, including weekday as well as weekend departures and returns. Our agents operated in parallel and submitted identical reservation requests to all online travel agents and airlines' websites simultaneously in order to minimize price variations that may arise from the timing of ticket requests.

Consistent with prior research on airline pricing, we consider only coach class, nonrefundable, round-trip tickets. Further, to control for any price difference that may be attributed to differences in flight duration or the number of connections on any given route, we restrict our attention to non-stop flights between an origin and a destination. Since non-stop flights were not available in 28 routes, our data set is reduced to 472 markets with 272,362 unique tickets and final prices, including taxes and fees, offered by fourteen largest domestic carriers $^{5}$.

Second, we used the Origin and Destination Survey (DB1B) from the Bureau of Transportation Statics (BTS) for the corresponding routes and carriers in the second and third quarters of 2004 to collect prices on transacted tickets and compute the market shares of individual airlines in each origin-destination pair. DB1B is a $10 \%$ sample of all tickets sold by

\footnotetext{
${ }^{4}$ The fourteen major carriers are American, Alaska, Continental, Delta, United, US Airways, Southwest, JetBlue, Frontier, America West, AirTran, ATA, and Spirit.

5 Spirit Airlines had been dropped from our subsequent analysis due to insufficient number of observations.
} 
reporting carriers, including origin, destination and other itinerary details of passengers transported. This data contains sales from both online and offline channels, and is used in our later analysis to check the robustness of our findings that are based on the online pricing data we gathered from the Internet. In addition, we used the Air Carrier Statistics (Form 41 Traffic and 298C Summary Data) and Air Carrier Financial Reports (Schedule P-12) provided by the BTS to assemble data on airlines' operational details (e.g. cost per available seat-mile, aircraft types and sizes, frequency of flights, etc.), as well as information on the respective markets (e.g. origin-destination distance, hub information, etc.).

By combining these various sets of data, we yielded a complete profile of all relevant variables at the ticket level that allowed us to examine the effects of various market- and firmspecific factors on airline pricing. We subsequently eliminated routes where the dominant carrier has over $90 \%$ market share. Our final data set consists of 209,558 observations from 268 markets. Table 3 reports the descriptive statistics of our data. 
Table 3: Descriptive Statistics $(\mathrm{N}=\mathbf{2 0 9 , 5 5 8 )}$

\begin{tabular}{|c|c|c|c|c|c|c|c|c|c|c|c|c|c|c|c|c|c|}
\hline & MEAN & STD & Min & $\operatorname{Max}$ & \multicolumn{13}{|c|}{ Correlation Matrix } \\
\hline price & 337.87 & 262.71 & 89.00 & 2959.00 & 1.00 & & & & & & & & & & & & \\
\hline$E D L P$ & 0.12 & 0.33 & 0.00 & 1.00 & -0.42 & 1.00 & & & & & & & & & & & \\
\hline$B U S$ & 0.50 & 0.50 & 0.00 & 1.00 & 0.02 & 0.02 & 1.00 & & & & & & & & & & \\
\hline$D D 7$ & 0.25 & 0.43 & 0.00 & 1.00 & 0.18 & 0.01 & -0.01 & 1.00 & & & & & & & & & \\
\hline DD14 & 0.25 & 0.43 & 0.00 & 1.00 & 0.00 & -0.01 & 0.00 & -0.33 & 1.00 & & & & & & & & \\
\hline$D D 21$ & 0.25 & 0.44 & 0.00 & 1.00 & -0.09 & 0.00 & 0.00 & -0.33 & -0.34 & 1.00 & & & & & & & \\
\hline freq & 42.40 & 39.61 & 0.00 & 192.08 & -0.21 & 0.36 & -0.01 & 0.00 & -0.01 & 0.00 & 1.00 & & & & & & \\
\hline$h u b$ & 0.74 & 0.44 & 0.00 & 1.00 & -0.03 & -0.08 & -0.01 & 0.00 & 0.00 & 0.00 & 0.37 & 1.00 & & & & & \\
\hline RTshare & 0.54 & 0.31 & 0.00 & 1.00 & -0.23 & 0.49 & 0.01 & 0.00 & -0.02 & 0.01 & 0.57 & 0.28 & 1.00 & & & & \\
\hline RTherf & 0.57 & 0.22 & 0.00 & 1.00 & -0.31 & 0.48 & 0.02 & 0.01 & -0.02 & 0.01 & 0.19 & 0.01 & 0.68 & 1.00 & & & \\
\hline shorthaul & 0.37 & 0.48 & 0.00 & 1.00 & -0.44 & 0.29 & 0.02 & 0.01 & -0.01 & 0.01 & 0.04 & -0.07 & 0.20 & 0.37 & 1.00 & & \\
\hline$C A S M$ & 11.59 & 2.56 & 6.13 & 16.13 & 0.25 & -0.55 & -0.02 & 0.00 & 0.01 & 0.00 & -0.33 & -0.04 & -0.39 & -0.28 & -0.06 & 1.00 & \\
\hline EQUIPsize & \begin{tabular}{|l|}
139.21 \\
\end{tabular} & 21.40 & 72.00 & 249.00 & 0.02 & -0.06 & -0.01 & 0.00 & 0.01 & 0.00 & 0.03 & -0.09 & 0.03 & 0.01 & -0.21 & -0.09 & 1.00 \\
\hline
\end{tabular}




\subsection{Models}

An important characteristic of our data is that prices of individual tickets (level 1) are clustered within groups, defined by airline/route (level 2). Thus, prices of tickets written by a particular carrier are likely to be correlated due to the underlying pricing strategy, or the cost and operational structure of the airline. Similarly, ticket prices of different airlines in the same market (defined as a directional origin-destination pair) may also be correlated because of the common underlying demand characteristics, competitive forces and cost structure for that route. When data are clustered in this fashion, the resulting unit-level random errors are correlated (within group) and heteroscedastic (across groups), thus violating two critical assumptions of the OLS.

Hierarchical linear models (HLM) provide a way to overcome these problems by accounting for the partial dependence of individual observations within a group and for heterogeneity across groups. This approach has been recommended for the analysis of airline data by Borenstein and Rose (1994), as well as in two recent studies of price dispersion in the area of information systems by Venkatesan, et al., (2006) and Chellappa, et al., (2011).

The fundamental idea behind HLM is that separate analyses are performed for each of the units at the lowest level of a hierarchical structure, while both individual- and group-level unit variances in the outcome measure are examined through simultaneous estimation of between-group variances and the effects of independent variables at each level. The total variance in the outcome is then divided into the parameter variance and error variance components. Unlike OLS, hierarchical models estimate residuals from different levels separately and account for the covariance structure among group-level regression estimates; not only does this provide more accurate group effect estimates than traditional methods that systematically underestimate them (Raudenbush and Bryk 1989), but it also allows one to model explicitly both within- and between- group variances as well as their effects on the outcome while maintaining the appropriate level of analysis (Griffin and Hofman 1997).

One additional advantage of the HLM approach is that it allows us to incorporate airline and market characteristics into the model while still producing accurate estimates of the grouplevel effects and valid tests of confidence intervals (Mendro et al. 1995) - which are typically ignored by OLS (Bryk and Thum 1989). In addressing the multilevel nature of data, traditional 
fixed effects models use dummy variables to "absorb" all heterogeneities across different group units; as a result, level-two variables (airline and route characteristics) are excluded from the model because they are confounded with the group fixed effects (airline and route dummies) and result in multicollinearity problems. In our current context, this implies that airline- and market-specific attributes cannot be explicitly accounted for in the model, thus largely limiting our ability to draw inferences on the possible moderating effects of these characteristics on the relationship between other explanatory variables (such as pricing strategy) and ticket prices. While typically this can be resolved by incorporating interactions between the explanatory variables and group-level dummies into the model, when the number of groups (such as origindestination pairs) is large, the interaction approach becomes impractical as it results in a large number of parameters and over-identification of the model.

Our econometric estimation aims to provide an understanding of firms' pricing strategies through two distinct measures. The first is price - which is self-explanatory in its ability to describe pricing strategy. In the price model, a positive (negative) coefficient for an independent variable suggests that the variable is correlated with a higher (lower) ticket price. The second dependent variable is "price variance" - commonly in IS literature this variable has only been used for studying market level dispersion in prices across firms. However, the marketing literature has shown how variance in prices of a single firm is in itself an execution of a corresponding pricing strategy. For example, the work by Hoch et al. (1994), Ho et al. (Ho, Tang et al.), and Shankar and Bolton (2004) use price variance at the firm-level to show some firms vary prices frequently while others do not; the theoretical reasoning behind creating multiple price points is that these different prices can appeal to different segments of consumers, allowing the firm to extract more surplus. Thus an examination of this dependent variable is critical to our understanding of the extent to which airlines like Southwest and JetBlue pursue discrimination compared with the other major carriers.

In the subsequent discussions, we use subscript $m$ to denote a market, subscript $k$ to denote a carrier, and subscript $c$ to denote ticket category. Model 1 investigates ticket-level prices (dependent variable: price $_{i k m c}$ ), while Model 2 examines the variance in prices of individual carriers within a given market, for each ticket category (dependent variable: $C V_{k m c}$ ). We treat both airline and route effects as random in Model 1; this is because level-1 units (individual tickets) are cross-classified by two separate level-2 units (airline and market). In Model 2, 
however, the dependent variable is an aggregate measure at the carrier-route-ticket category level. Following extant literature we treat only the route effect as random (Borenstein and Rose 1994).

\section{Model 1: Price level}

Consistent with extant literature on airline pricing, we employ log-transformation for most of our explanatory variables to capture their declining marginal effects on prices. The variables that are included in the model without any transformation are the dummy variables, market share (RTshare), and the corresponding Herfindahl index(RTherf) (Borenstein 1989).

Level 1 (ticket-level) model:

$$
\begin{aligned}
\ln \left(\text { price }_{i k m c}\right) & =\alpha_{0 k m c}+\alpha_{1 k m c} B U S_{i k m c}+\alpha_{2 k m c} D D 7_{i k m c}+\alpha_{3 k m c} D D 14_{i k m c}+\alpha_{4 k m c} D D 21_{i k m c}+\varepsilon_{i k m c} \\
\varepsilon_{i k m c} & \sim N\left(0, \sigma^{2}\right)
\end{aligned}
$$

In this model, the dependent variable price $_{i k m c}$ denotes the price of ticket $i$ offered by carrier $k$ in market (route) $m$ in a given ticket category $(c)$.

Level 2 (airline- and market-level) model:

$$
\begin{aligned}
\alpha_{0 k m} & =\beta_{0}+\gamma_{01} \text { EDLP }_{k}+\gamma_{02} \ln \left(\text { freq }_{k m}\right)+\gamma_{03} \text { hub }_{k m}+\gamma_{04} \text { RTshare }_{k m} \\
& +\gamma_{05} \text { RTherf }_{m}+\gamma_{06} \text { shorthaul }_{m}+\gamma_{07} \ln \left(\text { CASM }_{k}\right)+\gamma_{08} \ln \left(\text { EQUIP }_{\text {size }}\right) \\
& +\gamma_{09}\left(\text { EDLP }_{k} \times \text { shorthaul }_{m}\right)+\gamma_{10}\left(\text { EDLP }_{k} \times \text { hub }_{k m}\right)+u_{00 k}+u_{00 m}+u_{0 k m} \\
\alpha_{1-4 k m} & =\gamma_{1-4 k m}+\delta_{1-4 k m} \text { EDLP }_{k} \\
u_{00 k} & \sim N(0, \varphi) \\
u_{00 m} & \sim N(0, \tau) \\
u_{0 k m} & \sim N(0, \psi)
\end{aligned}
$$

The full model (after rearranging terms and renaming the coefficients):

$$
\begin{aligned}
\ln \left(\text { price }_{i k m c}\right) & =\alpha+\beta_{1} E D L P_{k}+\beta_{2} B U S_{i k m c}+\beta_{3} D D 7_{i k m c}+\beta_{4} D D 14_{i k m c}+\beta_{5} D D 21_{i k m c} \\
& +\beta_{6} \ln \left(\text { freq }_{k m}\right)+\beta_{7} h u b_{k m}+\beta_{8} \text { RTshare }_{k m}+\beta_{9} \text { RTherf }_{m} \\
& +\beta_{10} \text { shorthaul }_{m}+\beta_{11} \ln \left(\text { CASM }_{k}\right)+\beta_{12} \ln \left(E Q U I P s i z e_{k m}\right) \\
& +\beta_{13}\left(E D L P_{k} \times B U S_{i k m c}\right)+\beta_{14}\left(E D L P_{k} \times D D 7_{i k m c}\right)+\beta_{15}\left(E D L P_{k} \times D D 14_{i k m c}\right) \\
& +\beta_{16}\left(E D L P_{k} \times D D 21_{i k m c}\right)+\beta_{17}\left(E D L P_{k} \times \text { shorthaul }_{m}\right)+\beta_{18}\left(E D L P_{k} \times h u b_{k m}\right)+\varepsilon_{i k m}
\end{aligned}
$$

where

$$
\alpha=\beta_{0}+u_{00 k}+u_{00 m}+u_{0 k m}
$$


Equation (3) is the basic model to be estimated. Interactions between the EDLP identifier and various ticket categories (Saturday night stay-over and advance purchase periods) and market characteristics (short-haul and hub) are included to capture any potential differences in the pricing approach of EDLP versus other major carriers due to differences in their segmentation approach and operational/cost differences in various types of markets. $\beta_{0}$ represents the overall intercept; $u_{00 k}$ and $u_{00 m}$ are the random carrier and route effects, respectively. $u_{0 k m}$ is the random interaction effect. Finally, $\varepsilon_{i k m}$ is the white-noise error particular to the individual observation.

The variable $B U S$ identifies tickets without the Saturday night stay-over restriction, as these tickets are typically geared towards business travelers who have higher willingness to pay for a ticket (Gale and Holmes 1993; Dana 1998; Clemons, Hann et al. 2002). Consistent with prior work, we shall refer to these tickets without weekend restriction as "business tickets", while those that are with such restriction as "leisure tickets" (Chellappa et al. 2011). Readers are reminded that all tickets in our sample are restricted, coach class tickets.

Model 2: Price variance

Level 1 (airline-level) model:

$$
\begin{aligned}
C V_{k m c} & =\alpha_{0 m}+\alpha_{1 m} E D L P_{k}+\alpha_{2 m} B U S_{k m c}+\alpha_{3 m} D D 7_{k m c}+\alpha_{4 m} D D 14_{k m c}+\alpha_{5 m} D D 21_{k m c} \\
& +\alpha_{6 m} \text { freq }_{k m}+\alpha_{7 m} h u b_{k m}+\alpha_{8 m} \text { RTshare }_{k m}+\alpha_{9 m} \text { CASM }_{k}+\alpha_{10 m} \text { EQUIPsize }_{k m}+\varepsilon_{k m} \\
\varepsilon_{k m} & \sim N\left(0, \sigma^{2}\right)
\end{aligned}
$$

Level 2 (market-level) model:

$$
\begin{aligned}
\alpha_{0 m} & =\beta_{0}+\gamma_{11} \text { RTherf }_{m}+\gamma_{12} \text { shorthaul }_{m} \\
& +\gamma_{13}\left(E D L P_{k} \times \text { shorthaul }_{m}\right)+\gamma_{14}\left(E L P_{k} \times h u b_{k m}\right)+u_{0 m} \\
\alpha_{1 m} & =\gamma_{1 m} \\
\alpha_{2-5 m} & =\gamma_{2-5 m}+\delta_{2-5 m} E D L P_{k} \\
\alpha_{5-10 m} & =\gamma_{5-10 m} \\
u_{0 m} & \sim N(0, \tau)
\end{aligned}
$$

The full model (after rearranging terms and renaming the coefficients): 


$$
\begin{aligned}
C V_{k m c} & =\alpha+\beta_{1} E D L P_{k}+\beta_{2} B U S_{k m c}+\beta_{3} D D 7_{k m c}+\beta_{4} D D 14_{k m c}+\beta_{5} D D 21_{k m c} \\
& +\beta_{6} \text { freq }_{k m}+\beta_{7} \text { hub }_{k m}+\beta_{8} \text { RTshare }_{k m}+\beta_{9} \text { RTherf }_{m} \\
& +\beta_{10} \text { shorthaul }_{m}+\beta_{11} C A S M_{k}+\beta_{12} E Q U I P i z e_{k m} \\
& +\beta_{13}\left(E D L P_{k} \times B U S_{k m}\right)+\beta_{14}\left(E D L P_{k} \times D D 7_{k m}\right)+\beta_{15}\left(E D L P_{k} \times D D 14_{k m}\right) \\
& +\beta_{16}\left(E D L P_{k} \times D D 21_{k m}\right)+\beta_{17}\left(E D L P_{k} \times \text { shorthaul }_{m}\right)+\beta_{18}\left(E D L P_{k} \times h u b_{k m}\right)+\varepsilon_{k m}
\end{aligned}
$$

where

$$
\alpha=\beta_{0}+u_{0 m}
$$

The dependent variable in Model 2 is the coefficient of variation of prices, which is measured at the carrier-route-ticket category level and is constructed from the set of tickets written by an airline $(k)$ in a particular route $(m)$ for a given ticket category $(c)$. Ticket category is defined by restrictions imposed on a given ticket, namely Saturday night stay-over and advance purchase period. Thus,

$$
C V_{\mathrm{kmc}}=\frac{\sqrt{\frac{1}{I_{k m c}-1} \sum_{i}^{I_{k m c}}\left(\text { price }_{\mathrm{ikmc}}-\overline{\text { price }_{\mathrm{kmc}}}\right)^{2}}}{\overline{\text { price }_{\mathrm{kmc}}}} \text {, where } \overline{\text { price }_{\mathrm{kmc}}}=\frac{1}{I_{k m c}} \sum_{i}^{I_{k m c}} \text { price }_{\mathrm{ikmc}}
$$

Consistent with Borenstein and Rose (1994), we treat the route effect $\left(u_{0 m}\right)$ as random while capturing the airline effects using airline-specific variables $(E D L P$ and $C A S M)$. Note that since each observation for a given airline-market $(\mathrm{km})$ pair is aggregated at the ticket category level, the definitions of various ticket categories (BUS, DD7, DD14, DD21) remain the same as in Model 1; e.g. for American Airlines on the FLL-LGA route, there is one coefficient of variation constructed for all business tickets requested one-week prior to departure; for this observation, $B U S=1, D D 7=1, D D 14=0, D D 21=0$.

\section{Model 3: Minimum price analyses}

A major impact brought about by technology is transparency in prices - with the sorting mechanisms and matrix display offered by the OTAs and airlines' own websites, consumers can easily compare prices with the lowest available fare in the market. While our price level analysis provides insights on the relative prices offered by EDLP and non-EDLP carriers, the standard econometric specification captures only the average price levels. To assess the true effects of technology, we develop two additional models that examine prices of EDLP vs. nonEDLP airlines with respect to the market minimum price: one that compares the relative 
likelihood of the two types of carriers offering the lowest price in the market, while another determines how far they usually stray from the market minimum.

Model 3a: Likelihood of prices being lowest in the market

$$
\operatorname{prob}\left(\min P_{k m}=\min P_{m}\right)=\Lambda\left(\beta_{0}+\beta_{1} E D L P_{k}\right)
$$

where $\min P_{k m}$ is the minimum price offered by carrier $k$ in market $m$, and $\min P_{m}$ is the lowest

fare available in the market. $\Lambda$ is the logistic function, given by $\frac{\exp \left(\beta_{0}+\beta_{1} E D L P_{k}\right)}{1+\exp \left(\beta_{0}+\beta_{1} E D L P_{k}\right)}$.

Model 3b: Distance between median price and market minimum

$$
\begin{aligned}
\text { Meddiff }_{k m} & =\alpha+\beta_{1} \text { EDLP }_{k}+\beta_{2} \text { hub }_{k m}+\beta_{3} \text { RTshare }_{k m}+\beta_{4} \text { RTherf }_{m} \\
& +\beta_{5} \text { shorthaul }_{m}+\beta_{6} \text { CASM }_{k}+\beta_{7} \text { EQUIP size }_{k m}+\varepsilon_{k m}
\end{aligned}
$$

where

$$
\alpha=\beta_{0}+u_{0 m}
$$

The dependent variable in Model 3b is the distance between the observed carrier's median ticket price and the lowest fare available in the market, formally defined as:

$$
\text { Meddiff }_{\mathrm{km}}=\operatorname{median}\left(\text { price }_{k m}\right)-\operatorname{minP}_{m}, \text { where } \min _{m}=\min \left\{p_{11 m}, p_{21 m} \ldots p_{i k m}\right\}
$$

Note that for models $3 \mathrm{a}$ and $3 \mathrm{~b}$, we restrict our attention to only the markets where EDLP carriers compete. Further, for these two analyses our primary interest is in the DB1B data, where the observed prices are actual fares selected by the consumers.

We have taken great cautions in addressing potential endogeneity issues that might occur at different levels in our models, and have performed additional robustness checks using alternative model specifications. Interested readers may refer to Appendix A for details. 


\section{Discussion of Results}

The raw coefficient estimates of model 1 are presented in Table 4 . We have conducted many tests on model specification and robustness, including standard tests for multicollinearity, Hausman test, and robustness tests based on analysis on the residuals, as well as various goodness of fit indices. The two highest VIF values in our models are 5.32 and 4.94, both fall below the critical level of 10, which indicate that multicollinearity is not an issue. Further, we performed Hausman tests for both route and airline random effects. The null hypothesis is equality of fixed and random effects estimates. The resulting test statistic is 0.1673 , which falls well below the critical value of 29.14 at the 99 percent confidence level for a Chi-square with 14 degrees of freedom ${ }^{6}$. These statistics indicate that the coefficient estimates from the random effects model are not significantly different from those that are obtained from the fixed effects model, and that the random effects specification produces consistent estimates. Further, from the second and third columns in Table 4 we can observe that the estimates of the airline- and route-route random effects are highly significant in the hierarchical linear models. These statistics suggest that ticket prices are clustered within both carrier and route; hence the results obtained from the fixed effects model would likely be misleading. The last three rows in the table compare the goodness of fit for three different specifications of Model 1: The two-stage least square with fixed effects (2SLS), the null hierarchical model (Null HLM), and the full cross-classified hierarchical model (Full HLM); the former two serve as baseline models for comparison.

The Full HLM fits the data better than the fixed effects model (2SLS) based on both BIC and the sum of residual-squared errors criteria; the sum of squared errors of the Full HLM is lower than that of the fixed effects model by $5.95 \%$. The amount of reduction in variance components $\hat{\varphi}, \hat{\tau}$, and $\hat{\psi}$ suggest that $72.05 \%$ of explainable variation in carrier means, $20.65 \%$ of explainable variation in route means, and $24.69 \%$ of explainable variation in the carrier-route means are explained by the variables incorporated in the Full HLM. In addition, the random error is reduced by $14.90 \%$ compared to the null model. All statistics indicate that the chosen variables provide excellent explanations for the pricing of airline tickets in the sample.

\footnotetext{
${ }^{6}$ Variables that are perfectly collinear with either airline- or route-fixed effects are excluded.
} 
Table 4: Results from Price-level Analysis (Model 1)

\begin{tabular}{|c|c|c|c|}
\hline \multirow[t]{2}{*}{ Variable $^{7}$} & \multicolumn{3}{|c|}{$\begin{array}{l}\text { Dependent Variable: Price } \\
\text { Estimate (standard error) }\end{array}$} \\
\hline & $2 \mathrm{SLS}$ & Null HLM & Full HLM \\
\hline Intercept & -- & & $\begin{array}{c}5.7589^{* * *} \\
(0.3875)\end{array}$ \\
\hline$E D L P$ & -- & & $\begin{array}{c}0.1931^{* * *} \\
(0.0694)\end{array}$ \\
\hline$B U S$ & $\begin{array}{c}0.1263^{* * *} \\
(0.0015)\end{array}$ & & $\begin{array}{c}0.1255^{* * *} \\
(0.0015)\end{array}$ \\
\hline$D D 7$ & $\begin{array}{c}0.3043^{* * *} \\
(0.0021)\end{array}$ & & $\begin{array}{c}0.3018^{* * *} \\
(0.0021)\end{array}$ \\
\hline$D D 14$ & $\begin{array}{c}0.079^{* * *} \\
(0.0021)\end{array}$ & & $\begin{array}{c}0.0772^{* * *} \\
(0.0021)\end{array}$ \\
\hline$D D 21$ & $\begin{array}{c}0.0015 \\
(0.0021)\end{array}$ & & $\begin{array}{c}0.0014 \\
(0.0020)\end{array}$ \\
\hline $\ln ($ freq $)$ & $\begin{array}{c}-0.0215 * * * \\
(0.0007)\end{array}$ & & $\begin{array}{c}-0.0240^{* * *} \\
(0.0036)\end{array}$ \\
\hline$h u b$ & $\begin{array}{c}-0.0937 * * * \\
(0.0040)\end{array}$ & & $\begin{array}{c}-0.0649 * * * \\
(0.0230)\end{array}$ \\
\hline$\overline{R \text { Tshare }}$ & $\begin{array}{c}0.1401^{* * *} \\
(0.01344)\end{array}$ & & $\begin{array}{c}0.1667^{* * * *} \\
(0.0822)\end{array}$ \\
\hline$\widehat{\text { RTherf }}$ & -- & & $\begin{array}{c}-1.5675^{* * *} \\
(0.3659)\end{array}$ \\
\hline shorthaul & -- & & $\begin{array}{c}-0.1993^{* * *} \\
(0.0775)\end{array}$ \\
\hline $\ln (C A S M)$ & -- & & $\begin{array}{c}0.3611^{* * *} \\
(0.0803)\end{array}$ \\
\hline $\ln (E Q U I P$ size $)$ & $\begin{array}{c}-0.01817^{*} \\
(0.0106)\end{array}$ & & $\begin{array}{l}-0.0408 \\
(0.0621)\end{array}$ \\
\hline$E D L P \times B U S$ & $\begin{array}{c}-0.2483^{* * *} \\
(0.0078)\end{array}$ & & $\begin{array}{c}-0.2474^{* * *} \\
(0.0075)\end{array}$ \\
\hline$E D L P \times D D 7$ & $\begin{array}{l}-0.0117 \\
(0.0109)\end{array}$ & & $\begin{array}{l}-0.0080 \\
(0.0106)\end{array}$ \\
\hline$E D L P \times D D 14$ & $\begin{array}{c}0.0495^{* * *} \\
(0.0110)\end{array}$ & & $\begin{array}{c}0.0480^{* * *} \\
(0.0107)\end{array}$ \\
\hline$E D L P \times D D 21$ & $\begin{array}{c}0.0820^{* * *} \\
(0.0109)\end{array}$ & & $\begin{array}{c}0.0834^{* * *} \\
(0.0106)\end{array}$ \\
\hline EDLP $\times$ shorthaul & $\begin{array}{c}-0.2045^{* * *} \\
(0.0183)\end{array}$ & & $\begin{array}{c}-0.2310^{* * * *} \\
(0.0825)\end{array}$ \\
\hline$E D L P \times h u b$ & $\begin{array}{c}0.2200 \\
(0.0776)\end{array}$ & & $\begin{array}{c}0.1375 \\
(0.0975) \\
\end{array}$ \\
\hline
\end{tabular}

$7 \widehat{\text { RTshare }}$ and $\widehat{\text { RTherf }}$ are fitted values generated from the instruments that we employ in addressing the endogeneity issues associated with market share and the Herfindahl index. Please refer to Appendix A for details. 


\begin{tabular}{|l|c|c|c|}
\hline $\begin{array}{l}u_{00 k} \\
\text { (airline random } \\
\text { effects) }\end{array}$ & -- & $\begin{array}{c}0.01145^{* *} \\
(0.0053)\end{array}$ & $\begin{array}{c}0.0032^{* *} \\
(0.002)\end{array}$ \\
\hline $\begin{array}{l}u_{00 m} \\
\text { (route random } \\
\text { effects) }\end{array}$ & -- & $\begin{array}{c}0.1705^{* * *} \\
(0.0158)\end{array}$ & $\begin{array}{c}0.1353^{* * *} \\
(0.0125)\end{array}$ \\
\hline $\begin{array}{l}u_{0 k m} \\
\text { (random interaction } \\
\text { effects) }\end{array}$ & -- & $0.02045^{* * *}$ & $(0.0015)$ \\
\hline$\varepsilon_{i k m}$ & $0.1115^{* * *}$ & $0.1235^{* * *}$ & $\begin{array}{c}0.0154^{* * *} \\
(0.0012)\end{array}$ \\
\hline$N$ & $20.0003)$ & 2095558 & $0.1051^{* * *}$ \\
\hline$-2 L L$ & 136716 & 159762 & 2095558 \\
\hline BIC & 136728 & 159762 & 125875.8 \\
\hline $\begin{array}{l}\text { Sum of residual- } \\
\text { squared }\end{array}$ & 23332.43 & 25798.27 & 219458.30 \\
\hline
\end{tabular}

In the following subsections, we shall interpret and discuss our results so as to i) extend our understanding of airline pricing for major carriers in online markets and ii) to shed light on the everyday low price strategy in the airline industry.

\subsection{Consumer segmentation and pricing}

In Section 2.1, based on prior research we had suggested that airlines will engage in discrimination when the opportunity to segment consumers on some basis is available. Two key possibilities were discrimination based on schedule flexibility (through advance purchase requirement) and intended purpose of the trip (business/leisure, through Saturday stay-over restriction). Data tells us that all airlines indeed create various ticket types to segment based on advance purchase period. Our results show that both major carriers and EDLP airlines employ similar segmentation strategy along this dimension, with ticket prices being consistently higher closer to flight departure. In particular, for tickets offered by the major carriers, those that are purchased within two weeks (coefficient $=0.0722$; standard error $=0.0021$ ) and one week (coefficient $=0.3018$; standard error $=0.0021)$ before departure are priced $8.03 \%^{8}$ and over $35 \%$ higher than those purchased four weeks in advance, respectively. Similarly, prices of

8 This is calculated as a $100 *(\exp (0.0772)-1)$; similar calculations are performed using the raw coefficient estimates of the corresponding variables in interpreting their effects on non-EDLP prices. 
tickets offered by Southwest and JetBlue increase as departure date approaches, from $8.84 \%^{9}$ for three-week advance purchase (coefficient $=0.0847$; standard error $=0.0104$ ) to up to $34.15 \%$ for one-week advance purchase (coefficient $=0.2938$; standard error $=0.0104$ ), compared to those that are purchased four weeks in advance. Our results imply that even in the post Internet-based search era, airlines retain the ability to differentiate travelers based on their opportunity costs/willingness to pay via advance purchase requirements. They also suggest that, despite their pursuit of EDLP, Southwest and JetBlue do not necessarily forgo the discrimination opportunity associated with travelers' opportunity cost of time.

Our findings with regards to Saturday stay-over (BUS) are somewhat surprising and counter to what is commonly understood about consumer segmentation in this industry; i.e. airlines create different fare rules depending on whether the return trip occurs on a weekday or weekend. Research has suggested that imposing a Saturday night restriction for low price tickets is a key way to differentiate travelers on their intended purpose of the trip, as business travelers have strong tendency to return home for the weekend (Associates 2002; Office of Aviation and International Affairs 2003). While indeed American, Delta and other major carriers follow this practice, Southwest and JetBlue appear to eschew such a form of discrimination. For example, tickets offered by the major carriers that do not require a Saturday stay-over $($ coefficient $=0.1255$; standard error $=0.0015)$ are priced higher $($ by $13.37 \%$ ) compared to tickets with such a requirement. Our data shows that for tickets with the same origin and departure date, American's prices are on average $\$ 51.04$ higher when the return trip is on a weekday as opposed to weekend; the same is observed for all major carriers such as Continental (higher by $\$ 44.29$ ) and United (higher by $\$ 34.82$ ), etc. Interestingly, this is true even with OTAs and airlines' own web sites presenting weekend and non-weekend fares side by side for comparison. Although the use of Saturday stay-over restriction as a means for discrimination is a generally understood concept, the actual effect of this restriction on ticket

\footnotetext{
${ }^{9}$ Since our model includes several dichotomous variables that interact with the EDLP dummy, care must be taken when inferring the main and interaction effects and in deriving overall implications from the model. The effects of one-week advance purchase on EDLP prices can be derived from summing the coefficients of $D D 7(0.3018)$ and $E D L P \times D D 7 \quad(-0.0080)=0.2938$. The percentage is derived as $100 *(\exp (0.2938)-1)$, while standard error is calculated using the corresponding elements in the variance-covariance matrix of the Beta coefficients: $\sqrt{\operatorname{Var}\left(\beta_{3}\right)+\operatorname{Var}\left(\beta_{14}\right)+2 \operatorname{cov}\left(\beta_{3}, \beta_{14}\right)}$. Similar calculations are performed when interpreting the effects of other variables on EDLP prices.
} 
prices has not been formally established in empirical studies on airline pricing due to the lack of time attribute in the data on transacted tickets widely used in extant literature.

On the other hand, Southwest and JetBlue tickets actually appear to be cheaper when the return trip occurs on a weekday. In particular, their prices are lower (by 12\%) for tickets that do not involve a Saturday stay-over $($ coefficient $=-0.1219$; standard error $=0.0074)$ than those that do. Our data shows that Southwest's tickets are on average priced $\$ 31.87$ lower when the return trip occurs on a weekday instead of weekend, while JetBlue's tickets are $\$ 41.93$ lower for the same. While at one end this can be interpreted to mean that these two airlines employ a discrimination of the reverse kind, caution must be exercised in interpreting this result. This is because Southwest and JetBlue do NOT practice discrimination based on round trip fares; hence the long-held notion of weekend-restriction may not be meaningful in interpreting their prices. This is an important deviation from our extant understanding of airline pricing.

Taken together, our findings suggest that schedule flexibility and the preference for returning on weekday/weekend are intrinsic demand characteristics of travelers, ones that are not likely to change as a result of the lowering of search cost and their ability to find better deals on alternative flight schedules. Indeed, we find that the major carriers continue to practice discrimination along both advance purchase and Saturday stay-over dimensions. On the other hand, for the two EDLP airlines which seem to go out of their way to maintain consistency in prices, it appears that the segmentation based on opportunity cost of time warrants discrimination but one based on round-trip (and hence weekend-based restriction) is apparently not. In digesting this result, we should also remember that the whole round-trip fare was originated in the airline industry as a way to manage disproportional utilization of aircrafts. Apparently this is not a problem for Southwest and JetBlue who manage their operations in a much different fashion.

\subsection{Operational differences and pricing}

In section 2.3, we had discussed the relationship between operational/cost-advantages and market characteristics (i.e. route distance and hub operation), and that they are also tightly associated with the types of equipment that airlines have chosen to operate. In this section, we 
examine how such factors come into play in the pricing decision of EDLP and HILO carriers respectively.

Observe that ticket prices for HILO carriers are lower in both short-haul markets (coefficient $=-0.1993$; standard error $=0.0775$. This corresponds to a lower fare by $22 \%$, compared with long-haul markets) and on routes where they maintain a hub (coefficient = -0.0649 ; standard error $=0.0230$. This corresponds to a lower fare by $6.28 \%$, compared with non-hub routes). Hence even though that HILO carriers incur higher costs of maintaining a larger variation of equipments and scheduling crews to operate different planes on different routes, the savings from doing so seem to justify their choices. In particular, the fact that these airlines charge lower prices on short-haul markets suggests that their equipment utilization is efficient, despite having larger plane sizes that may not be fuel efficient on those routes. Further, instead of leveraging their dominance at hub airports and charging a premium to extract the higher willingness to pay by travelers who enjoy the convenience of more connection choices and higher flight frequency, these airlines appear to pass on - at least part of - the cost savings they enjoy from economies of scale at hub airports to consumers. This observation is consistent with the theoretical speculation that airlines may use lower prices to create barriers to entry on routes where they have a strong presence at the endpoint airports (Borenstein 1989). Our results suggest that the primary focus of the HILO carriers in both short-haul routes and hub markets is to protect or gain market share through lowering prices.

Southwest and JetBlue, on the other hand, appear to differentiate themselves from their HILO competitors along these dimensions. In particular, while similar to HILO airlines' practice in that their tickets are also cheaper in short-haul markets (coefficient $=-0.4302$; standard error $=0.1073$ ), the extent to which EDLP carriers lower prices in these markets (by 35\%, compared to prices they charge in long-haul markets) is nearly twice to that of their HILO counterparts $(22 \%)$. The fact that Southwest and JetBlue are able to leverage cost advantages on short-haul routes to an extent that is unmatchable by their competitors is perhaps closely related to their choice of equipments: both of these airlines operate smaller flights that are most fuel-efficient for short-haul routes, and that they are also very particular in limiting the variation in plane sizes to save cost on maintenance. Our findings suggest that the savings on operational costs enjoyed by EDLP airlines in short-haul routes exceed those of their competitors, and that these airlines undercut their competitors and to maintain their "low price" image through significantly lowering prices in short-haul markets. 
On the other hand, we do not observe any significant difference between the prices that EDLP carriers charge in hub- vs. non-hub markets (coefficient $=0.0726$; standard error $=$ 0.0949). This finding suggests that perhaps these airlines do not benefit from the same scale economies as their HILO counterparts do at hub airports, while at the same time they also refrain from leveraging their airport dominance to command a premium on tickets.

\subsection{Price variance analysis}

Table 5 presents the results from our price variance analysis (Model 2). Observe from the full model (last column) that the EDLP main effect is negative and significant, while most of the interaction effects are either negative or non-significant. Note also that the major carriers vary their price consistency for different ticket categories and market types. For example, the negative and significant coefficient for BUS suggests that the prices on business tickets exhibit a narrower distribution compared to leisure tickets. Combining this observation with our finding from the price model, we can conclude that major carriers discriminate business travelers by charging consistently higher prices on tickets that do not require a Saturday stay-over. The positive and significant coefficients of $D D 7$ and $D D 14$ imply that prices of tickets offered by the major carriers are increasingly volatile towards flight departure.

Table 5: Results from Price Variance Analysis (Model 2) ${ }^{10}$

\begin{tabular}{|l|c|c|c|}
\hline \multirow{2}{*}{ Variable } & \multicolumn{3}{|c|}{ Dependent Variable: Coefficient of Variation } \\
& \multicolumn{3}{|c|}{ Estimate (standard error) } \\
\cline { 2 - 4 } & 2 SLS & Null HLM & Full HLM \\
\hline \multirow{2}{*}{ Intercept } & -- & & $\begin{array}{c}0.0568 \\
(0.0411)\end{array}$ \\
\hline \multirow{2}{*}{$E D L P$} & -- & & $\begin{array}{c}-0.0847^{* * *} \\
(0.0229)\end{array}$ \\
\hline \multirow{2}{*}{$B U S$} & $-0.0645^{* * *}$ & & $\begin{array}{c}0.0646^{* * *} \\
(0.0036)\end{array}$ \\
\hline \multirow{2}{*}{$D D 7$} & $(0.0036)$ & & $\begin{array}{c}0.0654^{* * *} \\
(0.0051)\end{array}$ \\
\hline DD14 & $0.0654^{* * *}$ & & $\begin{array}{c}0.0537^{* * *} \\
(0.051)\end{array}$ \\
\hline
\end{tabular}

\footnotetext{
${ }^{10}$ Frequency in Model 2 is collinear with route-share (a carrier-route level variable) and hence is dropped.
} 


\begin{tabular}{|c|c|c|c|}
\hline$D D 21$ & $\begin{array}{c}0.0070 \\
(0.0051)\end{array}$ & & $\begin{array}{c}0.0070 \\
(0.0051)\end{array}$ \\
\hline$h u b$ & $\begin{array}{c}0.0072 \\
(0.0088)\end{array}$ & & $\begin{array}{c}0.0059 \\
(0.0075)\end{array}$ \\
\hline$\overline{\text { RTshare }}$ & $\begin{array}{c}0.0403 \\
(0.0258)\end{array}$ & & $\begin{array}{c}0.0567^{* *} \\
(0.0231)\end{array}$ \\
\hline$\widehat{R T h e r f}$ & -- & & $\begin{array}{c}0.0138 \\
(0.0778)\end{array}$ \\
\hline shorthaul & -- & & $\begin{array}{c}0.0032 \\
(0.0162)\end{array}$ \\
\hline$C A S M$ & -- & & $\begin{array}{c}0.0059^{* * *} \\
(0.0010)\end{array}$ \\
\hline EQUIPsize & $\begin{array}{l}-0.0003 \\
(0.0002)\end{array}$ & & $\begin{array}{c}0.0000 \\
(0.0001) \\
\end{array}$ \\
\hline$E D L P \times B U S$ & $\begin{array}{c}0.0312^{*} \\
(0.0170)\end{array}$ & & $\begin{array}{l}0.0317^{*} \\
(0.0171)\end{array}$ \\
\hline$E D L P \times D D 7$ & $\begin{array}{l}-0.0256 \\
(0.0241)\end{array}$ & & $\begin{array}{c}-0.0248 \\
(0.0243)\end{array}$ \\
\hline$E D L P \times D D 14$ & $\begin{array}{c}-0.0433^{*} \\
(0.0241)\end{array}$ & & $\begin{array}{c}-0.0434^{*} \\
(0.0242)\end{array}$ \\
\hline$E D L P \times D D 21$ & $\begin{array}{c}0.0265 \\
(0.0240) \\
\end{array}$ & & $\begin{array}{c}0.0265 \\
(0.0242) \\
\end{array}$ \\
\hline$E D L P \times$ shorthaul & $\begin{array}{l}-0.0047 \\
(0.0431) \\
\end{array}$ & & $\begin{array}{l}-0.0403 \\
(0.0275) \\
\end{array}$ \\
\hline$E D L P \times h u b$ & $\begin{array}{c}0.0657 \\
(0.0431)\end{array}$ & & $\begin{array}{c}0.0264 \\
(0.0395)\end{array}$ \\
\hline $\begin{array}{l}u_{00 m} \\
\text { (route random } \\
\text { effects) }\end{array}$ & -- & $\begin{array}{c}0.0049^{* * *} * \\
(0.0005)\end{array}$ & $\begin{array}{c}0.0049^{* * *} \\
(0.0005)\end{array}$ \\
\hline$\varepsilon_{k m}$ & $\begin{array}{c}0.0166^{* * *} \\
(0.0003)\end{array}$ & $\begin{array}{c}0.0190^{* * *} \\
(0.0004)\end{array}$ & $\begin{array}{c}0.0167^{* * *} \\
(0.0003)\end{array}$ \\
\hline$N$ & 5422 & 5422 & 5422 \\
\hline$-2 L L$ & -5557.2 & -5621.4 & -6158.1 \\
\hline $\mathrm{BIC}$ & -5548.7 & -5610.2 & -6147.0 \\
\hline
\end{tabular}

(Negative values represent higher consistency/lower variability in prices)

We employ similar techniques in inferring the effects of the ticket-/market-specific variables on EDLP price variance as detailed in the previous subsection. A rather distinct picture emerges as we compare the price variability dimension between EDLP and major carriers: EDLP carriers appear to pursue a strategy of rigorously controlling variation in ticket prices. We summarize our findings in Table 6. 
Table 6: Summary of Findings from the Online Dataset

\begin{tabular}{|c|c|c|}
\hline \multirow{2}{*}{$\begin{array}{c}\text { Potential } \\
\text { Categories for } \\
\text { Segmentation }\end{array}$} & \multicolumn{2}{|c|}{ Discrimination through price levels } \\
\hline & EDLP Carriers & Other Major Carriers \\
\hline $\begin{array}{l}\text { Advance purchase } \\
\text { (Discrimination } \\
\text { based on } \\
\text { consumers' } \\
\text { opportunity cost) }\end{array}$ & $\begin{array}{l}\text { YES } \\
\text { Premium from travelers on } \\
\text { short notice }\end{array}$ & $\begin{array}{c}\text { YES } \\
\text { Premium from travelers on short } \\
\text { notice }\end{array}$ \\
\hline $\begin{array}{c}\text { Saturday } \\
\text { restriction } \\
\text { (Discrimination } \\
\text { based on } \\
\text { consumers' } \\
\text { opportunity cost) }\end{array}$ & $\begin{array}{c}\text { NO } \\
\text { No premium from } \\
\text { business-trip travelers } \\
\text { (one-way pricing rather } \\
\text { than round-trip pricing } \\
\text { does not allow) }\end{array}$ & $\begin{array}{c}\text { YES } \\
\text { Premium from business-trip } \\
\text { travelers }\end{array}$ \\
\hline $\begin{array}{l}\text { Short-haul } \\
\text { markets } \\
\text { (Discrimination } \\
\text { based on } \\
\text { operational } \\
\text { advantage) }\end{array}$ & $\begin{array}{c}\text { YES } \\
\text { Lower prices where } \\
\text { operational advantages } \\
\text { exist }\end{array}$ & $\begin{array}{l}\text { YES } \\
\text { Lower prices where operational } \\
\text { advantages exist }\end{array}$ \\
\hline $\begin{array}{l}\text { Hub markets } \\
\text { (Discrimination } \\
\text { based on } \\
\text { operational } \\
\text { advantage) }\end{array}$ & $\begin{array}{c}\text { NO } \\
\text { Hub not a factor } \\
\text { (Perhaps due to more } \\
\text { point-to-point operation } \\
\text { than traditional hub-and- } \\
\text { spoke) }\end{array}$ & $\begin{array}{l}\text { YES } \\
\text { Lower prices where operational } \\
\text { advantages exist }\end{array}$ \\
\hline
\end{tabular}

\begin{tabular}{|c|}
\hline Discrimination through price variance \\
\hline $\begin{array}{c}\text { EDLP Carriers vs. Other carriers } \\
\text { (Which carrier prices more consistently in each } \\
\text { EDLP }\end{array}$ \\
\hline Prices very consistent compared to other airlines \\
\hline EDLP \\
\hline Prices very consistent compared to other airlines \\
\hline EDLP \\
\hline \\
Erices very consistent compared to other airlines \\
\hline
\end{tabular}




\subsection{Technology and price transparency}

In section 2.6, we had raised questions about the technology-related choices of airlines. Indeed, anecdotal evidence points to the fact that Southwest Airlines completely eschews participation in any of the OTAs while JetBlue does the same while offering some selected fares and participates partially in one OTA. Both airlines primarily rely on selling tickets through their own web sites; in particular, Southwest had created its own GDSs and has generally adopted a posture different from other airlines. We primarily seek to understand the judiciousness of this choice through our empirical analyses particularly since "low" price airlines should benefit from flaunting and even being compared to other airlines. Our results bear out the full story.

The sorting and various other comparison mechanisms offered by the OTAs provide significant improvements in product and price transparency, allowing the consumer to expeditiously determine the lowest price in the marketplace. Such an impact of technology cannot be fully assessed by the standard econometric specification, which concerns the average price of an airline with relations to its competitors. Therefore, in addition to the above estimations, we conduct two empirical analyses: a simple Logit model to assess the probability of these two EDLP airlines offering the lowest fare in the marketplace, and a model that determines how far they usually stray from the market minimum. The results are presented in Tables 7 and 8 respectively.

Table 7: Results from Logistic Analysis (Model 3a)

\begin{tabular}{|l|c|}
\hline \multicolumn{1}{|c|}{ Variable } & $\begin{array}{c}\text { Estimate } \\
\text { (standard error) }\end{array}$ \\
\hline Intercept & $\begin{array}{l}-0.2055 \\
(0.2266)\end{array}$ \\
\hline$E D L P$ & $\begin{array}{l}0.5283^{* *} \\
(0.2266)\end{array}$ \\
\hline \multicolumn{2}{|c|}{ Odds Ratio Estimates } \\
\hline$E D L P(0$ vs. 1) & 2.877 \\
\hline
\end{tabular}


The odds ratio estimate from our Logit analysis (Table 7) suggests that the lowest price available in the market is nearly three times more likely to come from non-EDLP carriers than from EDLP airlines. In other words, for over $74 \%$ of the time a consumer can find the lowest fare in the market from non-EDLP carriers; while EDLP prices are the lowest for only $26 \%$ of the time. Thus the results clearly bear out that if EDLP carriers made the same technology choices as the other airlines it might become less viable for them to continue advertising themselves as a "low" price airline while not being found out. This observation leads to a natural question: given that their prices are not lowest most of the time, how exactly are Southwest and JetBlue able to sustain their low price position? The results from our analysis of median prices shed light on this issue.

Table 8: Results from Median Price Analysis (Model 3b)

\begin{tabular}{|c|c|}
\hline Variable & $\begin{array}{c}\text { D.V.: Meddiff } \\
\text { Estimate } \\
\text { (standard error) }\end{array}$ \\
\hline Intercept & $\begin{array}{c}279.0100^{* * *} \\
(53.5674)\end{array}$ \\
\hline$E D L P$ & $\begin{array}{c}-47.6996^{* * *} \\
(11.8680)\end{array}$ \\
\hline$h u b$ & $\begin{array}{l}15.6499 \\
(9.7930)\end{array}$ \\
\hline$\overline{\text { RTshare }}$ & $\begin{array}{c}74.8979 * * * \\
(23.9136)\end{array}$ \\
\hline$\overline{\text { RTherf }}$ & $\begin{array}{r}-131.3000 \\
(87.7919)\end{array}$ \\
\hline shorthaul & $\begin{array}{c}-93.6347^{* * *} \\
(25.7100)\end{array}$ \\
\hline$C A S M$ & $\begin{array}{c}-7.9141^{* * *} \\
(1.8252)\end{array}$ \\
\hline EQUIPsize & $\begin{array}{l}0.02625 \\
(0.1916)\end{array}$ \\
\hline $\begin{array}{l}u_{00 m} \\
\text { (route random effects) }\end{array}$ & $\begin{array}{c}1673.95^{* * *} \\
(451.48)\end{array}$ \\
\hline$\varepsilon_{k m}$ & $\begin{array}{c}593.70^{* * *} \\
(128.67)\end{array}$ \\
\hline $\mathrm{N}$ & 87 \\
\hline$-2 \mathrm{LL}$ & 828.3 \\
\hline
\end{tabular}




\begin{tabular}{|l|r|}
\hline BIC & 835.7 \\
\hline
\end{tabular}

The negative and significant coefficient of EDLP indicates that median fares of EDLP carriers are closer to lowest available price in the marketplace compared to those of non-EDLP airlines. In other words, a majority of EDLP tickets that get cleared correspond to those being priced at the lower end of the market spectrum. Taking the results of the above two analyses together, we can conclude that while EDLP prices are not necessarily the lowest in the market, they do tend to be attractive enough to consumers who are price conscious yet do not always hunt for the best deals.

It is also interesting to note at this point that American Airlines (AA) have made some very curious moves regarding their participation at OTAs. AA opted out from Orbitz in late 2010, which resulted in Expedia to pull their American offers from their websites. Shortly afterwards (in April 2011), American filed a lawsuit against Orbitz for "exclusionary and anticompetitive business practices" while at the same time reaching an agreement with Expedia to have their offers once again displayed by the OTA. While the industry suspected that AA withdrew from OTAs primarily to cut distribution cost, and later staged a return because they realized that the savings are not worth losing out large marketplaces, American seems to be reformulating their pricing and technology choices. In fact, at the same time AA accused Orbitz of anticompetitive conduct, they also announced the development of their own distribution channel, known as the "Direct Connect". Essentially, American is demanding OTAs to retrieve flight information directly from this new system rather than through the GDSs. Such moves perhaps indicate that American realizes both the potential offered by the OTAs and the threats of transparency associated with such technologies; thus in response, they develop a new channel that allow for the best of both worlds through selectively listing their most competitive offers on OTAs while presenting a different set of choices to consumers who visit their own website.

\subsection{Robustness check with DB1B data - How do EDLP prices clear?}

Generally, most pricing research has dealt with either posted or transacted prices, except a recent work by Chellappa et al. (2011) that considers both types of prices in their analysis of price dispersion. While posted prices are appropriate for investigating the pricing behavior of a firm, transacted prices are useful for drawing inferences with regards to the effectiveness, or even viability, of its pricing strategy. The BTS database (DB1B) on transacted tickets, albeit 
less granular, provides such an opportunity. We conduct the same analyses as discussed in the previous sections on this dataset, and present the corresponding coefficient estimates in Table $\mathbf{9}$.

Table 9: Analysis on Transacted Tickets

\begin{tabular}{|c|c|c|}
\hline Variable & $\begin{array}{c}\text { D.V.: Price } \\
\text { Estimate (standard error) }\end{array}$ & $\begin{array}{l}\text { D.V.: Coefficient of Variation } \\
\text { Estimate (standard error) }\end{array}$ \\
\hline Intercept & $\begin{array}{c}6.0704^{* * * *} \\
(0.3719)\end{array}$ & $\begin{array}{c}0.3364^{* * * *} \\
(0.0716)\end{array}$ \\
\hline$E D L P$ & $\begin{array}{l}-0.1184 \\
(0.0888)\end{array}$ & $\begin{array}{c}-0.0894^{* *} \\
(0.0471)\end{array}$ \\
\hline $\ln ($ freq $)$ & $\begin{array}{l}-0.0072 \\
(0.0051) \\
\end{array}$ & -- \\
\hline$h u b$ & $\begin{array}{c}0.0023 \\
(0.0206) \\
\end{array}$ & $\begin{array}{c}0.0759^{* * *} \\
(0.0161)\end{array}$ \\
\hline$\overline{\text { RTshare }}$ & $\begin{array}{c}0.4225^{* * *} \\
(0.0559)\end{array}$ & $\begin{array}{c}0.1539^{* * *} \\
(0.0393) \\
\end{array}$ \\
\hline$\overline{R T h e r f}$ & $\begin{array}{c}-1.0844^{* * *} \\
(0.2331)\end{array}$ & $\begin{array}{c}-0.4014^{* *} \\
(0.1282)\end{array}$ \\
\hline shorthaul & $\begin{array}{c}-0.1144^{* *} \\
(0.0499) \\
\end{array}$ & $\begin{array}{l}0.0509^{*} \\
(0.0270) \\
\end{array}$ \\
\hline $\ln (C A S M)$ & $\begin{array}{c}0.0269 \\
(0.0998) \\
\end{array}$ & -- \\
\hline $\ln ($ EQUIPsize $)$ & $\begin{array}{l}-0.0122 \\
(0.0527) \\
\end{array}$ & -- \\
\hline$C A S M$ & -- & $\begin{array}{c}0.0100^{* * *} \\
(0.0026)\end{array}$ \\
\hline EQUIPsize & -- & $\begin{array}{l}0.0005^{*} \\
(0.0003) \\
\end{array}$ \\
\hline$E D L P \times$ shorthaul & $\begin{array}{c}-0.3270^{* * * *} \\
(0.0896) \\
\end{array}$ & $\begin{array}{l}-0.0762 \\
(0.0620) \\
\end{array}$ \\
\hline$E D L P \times h u b$ & $\begin{array}{c}0.0787 \\
(0.0610) \\
\end{array}$ & $\begin{array}{l}-0.0601 \\
(0.0537) \\
\end{array}$ \\
\hline $\begin{array}{l}u_{00 k} \\
\text { (airline random effects) }\end{array}$ & $\begin{array}{c}0.0056^{* *} \\
(0.0028) \\
\end{array}$ & -- \\
\hline $\begin{array}{l}u_{00 m} \\
\text { (route random effects) }\end{array}$ & $\begin{array}{c}0.0467^{* * *} \\
(0.0048)\end{array}$ & $\begin{array}{c}0.0064^{* * *} \\
(0.0013)\end{array}$ \\
\hline $\begin{array}{l}u_{0 \mathrm{~km}} \\
\text { (random interaction } \\
\text { effects) }\end{array}$ & $\begin{array}{c}0.0085^{* * *} \\
(0.0010)\end{array}$ & -- \\
\hline$\varepsilon_{i k m}$ & $\begin{array}{c}0.2232^{* * *} \\
(0.0013)\end{array}$ & -- \\
\hline$\varepsilon_{k m}$ & -- & $\begin{array}{c}0.0156^{* * *} \\
(0.0012)\end{array}$ \\
\hline $\mathrm{N}$ & 61655 & 615 \\
\hline$-2 \mathrm{LL}$ & 84014.5 & -582.7 \\
\hline
\end{tabular}


Though we are not able to make one-to-one comparisons with the estimates derived from the online dataset (due to the lack of information on timing of ticket purchase on transacted tickets) our results from the DB1B dataset are fully consistent with those reported earlier. Specifically, from the first column in Table 9, we can observe that EDLP prices are lower in short-haul markets than in long-haul markets by $35.69 \%$ (Coefficient $=-0.4414$; standard error $=0.0968$ ), while not being significantly different in hub versus non-hub markets (Coefficient $=$ 0.0810; standard error $=0.0600)$. Further, our results also suggest that EDLP airlines do not vary the consistency of their prices in the various markets. The coefficient estimates presented in the second column suggest that the variances in EDLP prices are not statistically different in short-haul versus long-haul markets (Coefficient $=-0.0253$; standard error $=0.0638$ ) or in hub versus non-hub markets (Coefficient $=0.0158$; standard error $=0.0522$ ). These results are virtually identical to those derived from our analysis on the online dataset, both in terms of price level and variability across various market segments.

\section{Conclusion and implications for research and practice}

Given nearly 50 percent of airline tickets are now sold over the Internet and in view of the fact that Internet impacts search costs, price and product transparency and price dispersion, IS research has shown renewed interest in airline pricing in the recent past. A relevant question is if offline pricing strategies pursued for many decades translate well online and are indeed pursued. Though much is known about airline pricing in general, as it has been studied extensively since the deregulation in the 70s, in all extant studies (economics, management and IS) in the airline industry, two major airlines have been left out (with the exception of Chellappa, et al (2011)). One of them, Southwest Airlines, is today the second largest carrier (after the merged Delta \& Northwest) and accounts for over 14 percent of the market. In the absence of our study, one could possibly presume that Southwest and JetBlue follow the basic tenets of airline pricing as others before them. There are, however, two reasons to reexamine principles of airline pricing that are of particular interest - first, the airlines advertise the practice of a pricing strategy hitherto unobserved in the airline industry called everyday low price (EDLP); and second, certain 
technological choices made by these two airlines appear distinct and different from their competitors.

In this paper, we test extant theories of price discrimination in the airline industry while including ticket prices from the two EDLP airlines. While we know from literature that the major airlines significantly vary their prices based on advance purchase and Saturday night restrictions, and engage in hub-based pricing, the choices of EDLP airlines in these regards are not necessarily obvious. There exists a natural tension between varying prices when opportunities for discrimination and segmentation present themselves and the need to preserve their consistent low-price image.

Our empirical findings reveal a number of interesting aspects of airline pricing as observed today in both their online and offline offerings through both their own Web sites and through OTAs. Consistent with a recent literature on market transparency in airline prices (Granados, Gupta et al. 2006) our research confirms that many elements of market segmentation and price discrimination are quite alive in the pricing strategies of all non-EDLP carriers. We continue to observe a significant variance in the range of prices they offered, and that they discriminate against consumers with higher opportunity costs and business travelers who would not like to be subjected to Saturday-night stays. Furthermore, they also vary their prices with hub-operations. On the other hand, the EDLP airlines exhibit remarkable consistency in prices almost impervious to any changing market/consumer conditions. While opportunity costs of the travelers appear too high a factor to pass over, the EDLP airlines generally do not vary their prices with other factors. Though, with cost-based advantages of short-haul flights, they do undercut their competition with significantly lower prices in these segments. Thus our research demonstrates that alternative pricing strategies that are different and distinct from conventional wisdom in this sector are indeed being practiced.

What is interesting and relevant to IS researchers, however, is the fact that successful practice of these strategies requires judicious choices in accompanying technologies. Little has been written about Southwest Airlines' (one that has been in operation since the seventies) choice of developing its own home-grown reservations systems in lieu of full-fledged participation in a platform called Computerized Reservation Systems (CRSs, now called Global Distribution Systems, GDSs and adopted by all other airlines). These CRSs provide the 
fundamental platform for ticket creation and sales that are accessible by both physical and now online travel agents. In addition to providing simple automation advantages (Banker and Johnston 1995; Duliba, Kauffman et al. 2001), the CRSs are known to have played a crucial and strategic role in market transparency of prices (Duliba, Kauffman et al. 2001; Granados, Kauffman et al. 2008). Further, with regards to offering tickets through online travel agencies (OTAs) like Orbitz, Expedia, Travelocity, etc., Southwest and JetBlue have again chosen to not use these intermediary services on the Internet - instead they rely primarily on their own Websites. Simply put, why would these airlines choose to forego the larger marketplace offered by these OTAs?

Our empirical analysis sheds light on this question. First, we find that independent of market segments, EDLP airlines are focused on maintaining price consistency; this suggests that the lowered menu cost and complex price points made possible by the sophisticated CRSs are not attractive to them. Second, we find that while EDLP tickets are "on an average" lower, at any given point in time the probability of getting the lowest price ticket in a given market from an EDLP airline is only 26 percent. That is over 70 out of 100 times a major carrier might offer a cheaper ticket. This observation needs to be reconciled with the fact the EDLP prices appear consistent and on an average lower than the market to consumers at large. A more granular analysis of the distribution of prices, rather than just the average price-point (as a regular regression will reveal) or the lowest prices in the market (as our Logit analysis reveals), bears the answer. Our median price analysis suggests that the EDLP price distribution is to the left of the distribution of market prices, suggesting that it leaves the upper and lower tail of the price distribution to the others. Thus our work reveals a careful construction of prices and the full cognizance of the impact of search tools which primarily serve the purpose of revealing the lower tail to the consumers.

\section{Implications for research and practice}

The implication for academics is quite straight forward - it is important to incorporate firms' overall pricing strategy (not just their product/market-specific prices) in competitive analysis of

prices. Furthermore, we also need to evaluate other tools to conduct these analyses particularly when firms out a distribution of prices in the market. There are some recent works on functional 
regressions that might be helpful in this regard, although these have largely been crafted for time-series data.

From a practice point of view, it is clear that EDLP - which is about the imparting of a low-price image in the minds of the consumer - is not about having the lowest prices in the market. Interestingly, it is not also about basket-shopping alone although that is the context in which it has been empirically studied in the marketing literature. Traditionally, groceries and retail stores such as Wal-Mart have relied on basket-shopping (multi-unit demand), which enforces the notion that even if individual products may be on sale elsewhere, a consumer believes that on an average he is better off shopping at the EDLP store. Note that at its core, EDLP relies on the fact that the consumer will not be able search for the lowest price for each product in the basket AND it will be physically costly for him to collect the basket of goods in this fashion. While the physical concept of a basket does not exist in the airline context, extant research in marketing (Hoch et al. 1994) does identify Southwest Airlines as an early practitioner of EDLP. Our research suggests that while physical basket is one manifestation, a temporal, virtual basket is equally relevant since the core of EDLP success is not the basket, rather the "unattractiveness" of search (through continuous conditioning of low-prices on the part of the EDLP firm). Airline passengers usually buy multiple tickets over time, and Southwest and JetBlue work towards the goal that in the absence of a significant search, their tickets appeal to this segment.

A comparison of posted and transacted prices suggests that this works, i.e., EDLP firms seem to set prices that are not the lowest but are geared towards the lower end in the market, and the tickets that they offer are cleared in the market at these prices. This suggests that there is indeed a consumer population even online, which is representative of the EDLP firms' target set. In other words, the expected cost of search for these consumers is still high compared to buying from the EDLP airlines. This is indeed why we continue to observe dispersion of prices online.

In attempting to understand the transference of EDLP practice offline to online, one only needs to observe Wal-Mart's online strategy. It appears that this EDLP giant is cognizant of the difficulty of this practice given the wide presence of price-bots and other search tools, and is conscious of the need to align costs with the front-end practice, a fact that we have noted with airlines as well - EDLP practice goes hand-in-hand with low equipment variance and low 
operating costs. Wal-Mart views its online store largely as just another channel. Evidence suggests that 90 percent of its online customers shop in its physical stores and that over 40 percent of its online sales are "Site to Store". This latter strategy is primarily geared towards taking advantage of its logistics capabilities and thus reducing cost. Indeed, Wal-Mart makes it clear that its online prices can vary from the store prices which themselves vary store to store. In other words, Wal-Mart considers its online strategy as a channel to divert traffic to its offline store where it vigorously pursued its EDLP practice. Our research suggests clear possibilities exist online as well, at least for some product markets. 


\section{References}

Associates, H. 2002. The Internet Travel Industry: What Consumers Should Expect and Need to Know, and Options for a Better Marketplace. Consumer Reports, available at: http://www.consumerwebwatch.org/pdfs/internet-travel-industry.pdf.

Banker, R. D. and H. H. Johnston. 1993. An Empirical Study of Cost Drivers in the U.S. Airline Industry. The Accounting Review 68(3)576-601.

Banker, R. D. and H. H. Johnston. 1995. An Empirical Study of the Business Value of the US Airlines' Computerized Reservations Systems. Journal of Organizational Computing 5(3)255-275.

Bell, D. R. and J. M. Lattin. 1998. Shopping Behavior and Consumer Preference for Store Price Format: Why "Large Basket" Shoppers Prefer EDLP. Marketing Science 17(1)66-88.

Berry, S. 1990. Airport Presence as Product Differentiation. The American Economic Review 80(2)394399.

Berry, S., M. Carnall and P. T. Spiller. 1997. Airline Hubs: Costs, Markups and the Implications of Customer Heterogeneity. NBER Working Paper \#5561.

Borenstein, S. 1989. Hubs and High Fares: Dominance and Market Power in the U.S. Airline Industry. The RAND Journal of Economics 20(3)344-365.

Borenstein, S. 1991. The Dominant-Firm Advantage in Multi-Product Industries: Evidence from the U.S. Airlines. Quarterly Journal of Economics 106(November).

Borenstein, S. and N. L. Rose. 1994. Competition and Price Dispersion in the U.S. Airline Industry. The Journal of Political Economy 102(4)653-683.

Bryk, A. S. and Y. M. Thum. 1989. The Effects of High School Organization on Dropping Out: An Exploratory Investigation. American Educational Research Journal 26353-383.

Campbell, C., G. Ray and W. A. Muhanna. 2005. Search and Collusion in Electronic Markets. Management Science 51(3)563-585. 
Chellappa, R. K., R. G. Sin and S. Siddarth. 2011. Price-Formats as a Source of Price Dispersion: A Study of Online and Offline Prices in the Domestic US Airline Markets Information Systems Research 22(1).

Clemons, E. K., I. Hann and L. M. Hitt. 2002. Price Dispersion and Differentiation in Online Travel: An Empirical Investigation. Management Science 48(4)534-549.

Dana, J. D. 1998. Advance-Purchase Discounts and Price Discrimination in Competitive Markets. The Journal of Political Economy 106(2)395-422.

Desiraju, R., H. Nair and P. Chintagunta. 2004. Diffusion of New Pharmaceutical Drugs in Developing and Developed Nations. International Journal of Research in Marketing 21341-357.

Duliba, K. A., R. J. Kauffman and H. C. Lucas. 2001. Appropriating Value from Computerized Reservation System Ownership in the Airline Industry. Organization Science 12(6)702-728.

Evans, W. N. and I. N. Kessides. 1994. Living by the "Golden Rule": Multimarket Contact in the U.S. Airline Industry. The Quarterly Journal of Economics 109(2)341-366.

Gale, I. L. and T. J. Holmes. 1993. Advance-Purchase Discounts and Monopoly Allocation of Capacity. The American Economic Review 83(1)135-146.

Gimeno, J. and E. Jeong. 2001. Multimarket Contact: Meaning and Measurement at Multiple Levels of Analysis. Multiunit Organization and Multimarket Strategy. J. A. C. Baum and H. Greve. JAI Press, London.

Granados, N., A. Gupta and R. J. Kauffman. 2006. The Impact of IT on Market Information and Transparency: A Unified Theoretical Framework. Journal of the Association for Information Systems March148-178.

Granados, N., A. Gupta and R. J. Kauffman. 2010. Information Transparency in Business-to-Consumer Markets: Concepts, Framework, and Research Agenda. Information Systems Research 21(2)207226. 
Granados, N., R. J. Kauffman and B. King. 2008. How Has Electronic Travel Distribution Been Transformed? A Test of the Theory of Newly Vulnerable Markets. Journal of Management Information Systems 25(2)73-95.

Griffin, M. A. and D. A. Hofman. 1997. Hierarchical Linear Models in Organizational Research: CrossLevel Interactions. Reseach Methods Forum 21-3.

Hausman, J. A. and W. E. Taylor. 1981. Panel Data and Unobservable Individual Effects. Econometrica 49(6)1377-1398.

Hayes, K. J. and L. B. Ross. 1998. Is Airline Price Dispersion the Result of Careful Planning or Competitive Forces? Review of Industrial Organization 13(5)523-541.

Ho, T.-H., C. S. Tang and D. R. Bell. 1998. Rational Shopping Behavior and the Option Value of Variable Pricing. Management Science 44(December)145-160.

Hoch, S. J., X. Dreze and M. E. Purk. 1994. EDLP, Hi-Lo, and Margin Arithmetic. Journal of Marketing 58(October)16-27.

Lal, R. and R. C. Rao. 1997. Supermarket Competition: The Case of Every Day Low Pricing. Marketing Science 16(1)60-80.

Mendro, R. L., W. J. Webster, K. L. Bembry and T. H. Orsak. 1995. An Application of Hierarchical Linear Modeling in Determining School Effectiveness. Mimeo, Annual Meeting of the American Educational Research Association, San Francisco, CA.

Morrison, S. A. 2001. Actual, Adjacent, and Potential Competition: Estimating the Full Effect of Southwest Airlines. Journal of Transport Economics and Policy 32239-256.

Neels, K. 2000. Congestion Pricing and the Economic Regulation of Airports. Airports in the 21st Century: Proceedings of a Conference. J. M. Rakas, G. W. Blomme and G. Gosling Transportation Research Board, The National Academies. Washington, D.C. 60-66.

Nevo, A. 2001. Measuring Market Power in the Ready-to-eat Cereal Industry. Econometrica 69(2)307342. 
Office of Aviation and International Affairs, A. A. 2003. Fare Structure Experimentation. Domestic Aviation Competition Issue Brief Number 21, available online: http://ostpxweb.dot.gov/aviation/domestic-competition/1Q03-AmericaWestpricingstructure.pdf.

Png, I. 2001. Managerial Economics. Wiley-Blackwell.

Raudenbush, S. W. and A. S. Bryk. 1989. Quantitative Models for Estimating Teacher and School Effectiveness. Multilevel Analysis of Educational Data. R. D. Bock. Academic Press, San Diego, CA: 205-232.

Shankar, V. and R. N. Bolton. 2004. An Empirical Analysis of Determinants of Retailer Pricing Strategy. Marketing Science 23(1)28-49.

Stavins, J. 2001. Price Discrimination in the Airline Market: The Effect of Market Concentration. Review of Economics and Statistics 83(1)200-202.

Venkatesan, R., K. Mehta and R. Bapna. 2006. Understanding the confluence of retailer characteristics, market characteristics and online pricing strategies. Decision Support Systems 42(3)1759-1775. 


\section{Appendix A: Endogeneity, Instrument and Additional Robustness Checks}

\section{Endogeneity and Instrument}

It is reasonable to expect that an airline's share of passenger on a route (RTshare), as well as the Herfindahl index constructed from this variable (RTherf), to be endogenous to the price that it charges; in fact, a Hausman specification test does reject exogeneity for $R$ Tshare and RTherf. This observation of a potential for endogeneity has indeed been recognized in the economics literature and a solution architected in the form of an instrument and two-stage least squares (Borenstein 1989). We largely follow this prescription in handling our dataset as well. We construct RTshare based on market share information obtained from the second quarter of 2004 (one quarter prior to our data collection); hence it is reasonable to argue that prices of tickets offered by an airline (in the current period) is a function of its market share (in the previous period), rather than the other way around. However, if market shares of the respective airlines are relatively stable - which is indeed the case for most of the routes - then statistically the potentially endogenous variables can still be correlated with the error term. Following Borenstein (1989) and Borenstein and Rose (1994), we use the geometric share of enplanements of an observed carrier at the endpoints of a given route as the instrument for its market share, and later use it to construct the instrument for RTherf. The geometric enplanement share of the observed airline $i$ on a given route is defined as follows:

$$
\operatorname{GENPSH}_{i}=\frac{\sqrt{E N P_{i 1} \cdot E N P_{i 2}}}{\sum_{j} \sqrt{E N P_{j 1} \cdot E N P_{j 2}}}
$$

where $j$ indexes all airlines; $E N P_{j 1}$ and $E N P_{j 2}$ are airline $j$ 's average daily passenger enplanements at the two endpoint airports on the observed route during the second quarter of 2004. In other words, GENPSH${ }_{i}$ is defined as the observed carrier's geometric mean of passenger enplanements at the endpoints of a route divided by the sum of the geometric mean of each carrier's enplanements at the endpoint airports across all carriers on the observed route.

We construct the instrument for RTherf using the square of the fitted value $\overline{\text { RTshare }}$ from the first-stage regression, plus a rescaled sum of squares of the shares of all other carriers: 


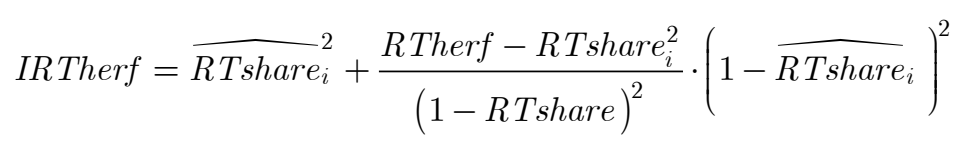

where $i$ indexes the observed airline. The rationale behind the second term in IRTherf is that the concentration of traffic on a route that is not served by the observed airline is exogenous to the price of the observed airline; for example, Delta's price on the Boston-LaGuardia Airport route does not affect the division of passengers between American and United. The rescaling ensures that the part in a Herfindahl index that is calculated for passengers who do not travel on the observed carrier remains unchanged. We then use IRTherf as the excluded exogenous variable in the first-stage regression of RTherf that generates $\overline{R \text { Therf }}$.

Careful readers may notice that in Model 1 RTshare is correlated not with the error at

the individual ticket level $\left(\varepsilon_{i k m}\right)$ but instead with the level-2 random interaction effect $\left(u_{0 k m}\right)$; the reason is that RTshare is defined at the carrier-route level, which is ticket-invariant. Standard procedures in the instrumental variable approach ignore the level-1-invariant nature of the latent effect, yielding an estimator that is biased at best and inconsistent at worst. We employ a method that makes use of the information available from level-1 exogenous variables in constructing the level-2 instrument based on Hausman and Taylor (1981). The basic idea behind this approach is that the effects of each level-1 exogenous variable in a level-2 instrument can be approximated by its mean at the corresponding level; hence the means of exogenous ticket-varying variables (e.g. $D D 7$ ), along with other ticket-invariant exogenous variables (e.g. freq), can be used as instruments for the endogenous ticket-invariant variables. Similar approaches have been used in other studies of the cereal market (Nevo 2001) and the diffusion of new pharmaceutical drugs (Desiraju et al. 2004).

\section{Additional robustness checks}

Table A1 presents the coefficient estimates of our fixed effects models on both the "low price" dimension (column 1) and "everyday" dimension (column 2). Note that while these estimates cannot be directly compared to those presented in Tables 4 and 5, we can observe from the airline fixed effects that ticket prices offered by the two EDLP carriers are generally more consistent, though not necessary lowest in the market, compared to those offered by the other airlines. Our findings are in line with the results that are presented in the paper. 
Table A1: Robustness checks with airline and route fixed effects

\begin{tabular}{|c|c|c|}
\hline & \multicolumn{2}{|c|}{$\begin{array}{c}\text { Estimate } \\
\text { (standard error) }\end{array}$} \\
\hline Variable & $\begin{array}{c}\text { Dependent Variable: } \\
\text { Price }\end{array}$ & $\begin{array}{c}\text { Dependent Variable: } \\
\text { C.V. }\end{array}$ \\
\hline$B U S$ & $\begin{array}{c}0.1170^{* * *} \\
(0.0015) \\
\end{array}$ & $\begin{array}{c}-0.0632^{* * *} \\
(0.0035) \\
\end{array}$ \\
\hline$D D 7$ & $\begin{array}{c}0.3039 * * * \\
(0.0021)\end{array}$ & $\begin{array}{c}0.0641^{* * *} \\
(0.0050)\end{array}$ \\
\hline$D D 14$ & $\begin{array}{c}0.0799^{* * *} \\
(0.0021)\end{array}$ & $\begin{array}{c}0.0515^{* * *} \\
(0.0050)\end{array}$ \\
\hline$D D 21$ & $\begin{array}{l}0.0045^{* *} \\
(0.0021)\end{array}$ & $\begin{array}{c}0.0081 \\
(0.0050) \\
\end{array}$ \\
\hline $\ln ($ freq $)$ & $\begin{array}{c}-0.0223^{* * *} \\
(0.0007) \\
\end{array}$ & -- \\
\hline$h u b$ & $\begin{array}{c}-0.0839^{* * *} \\
(0.0040)\end{array}$ & $\begin{array}{c}0.0086 \\
(0.0087)\end{array}$ \\
\hline$\overline{\text { RTshare }}$ & $\begin{array}{c}0.1227^{* * *} \\
(0.0134)\end{array}$ & $\begin{array}{c}0.0359 \\
(0.0256)\end{array}$ \\
\hline $\ln (E Q U I P$ size $)$ & $\begin{array}{c}-0.0244^{* *} \\
(0.0106) \\
\end{array}$ & -- \\
\hline EQUIPsize & -- & $\begin{array}{l}-0.0003 \\
(0.0002) \\
\end{array}$ \\
\hline American & $\begin{array}{c}0.1032^{* * *} \\
(0.0077)\end{array}$ & $\begin{array}{l}0.0370^{* *} \\
(0.0165)\end{array}$ \\
\hline Alaska & $\begin{array}{c}0.0307^{* * *} \\
(0.0103)\end{array}$ & $\begin{array}{l}-0.0034 \\
(0.0205)\end{array}$ \\
\hline Continental & $\begin{array}{c}0.0941^{* * *} \\
(0.0084)\end{array}$ & $\begin{array}{c}0.0237 \\
(0.0184) \\
\end{array}$ \\
\hline Delta & $\begin{array}{c}0.0954^{* * *} \\
(0.0077) \\
\end{array}$ & $\begin{array}{c}0.0552^{* * *} \\
(0.0176) \\
\end{array}$ \\
\hline Frontier $^{\dagger}$ & $\begin{array}{c}-0.0473^{* * *} \\
(0.0158)\end{array}$ & $\begin{array}{c}0.0719^{* * *} \\
(0.0268)\end{array}$ \\
\hline America West $^{\dagger}$ & $\begin{array}{c}-0.0914^{* * *} \\
(0.0140) \\
\end{array}$ & $\begin{array}{l}-0.0335 \\
(0.0203) \\
\end{array}$ \\
\hline Northwest & $\begin{array}{c}0.0523^{* * *} \\
(0.0093)\end{array}$ & $\begin{array}{c}0.0305 \\
(0.0210) \\
\end{array}$ \\
\hline $\mathrm{ATA}^{\dagger}$ & $\begin{array}{c}-0.1458^{* * *} \\
(0.0125)\end{array}$ & $\begin{array}{c}0.0428 \\
(0.0266) \\
\end{array}$ \\
\hline United & $\begin{array}{c}0.1521^{* * *} \\
(0.0079)\end{array}$ & $\begin{array}{c}0.0291 \\
(0.0169)\end{array}$ \\
\hline US Airways & $\begin{array}{c}0.1711^{* * *} \\
(0.0077)\end{array}$ & $\begin{array}{c}0.0478^{* * *} \\
(0.0164)\end{array}$ \\
\hline Southwest $^{\dagger \pm}$ & $\begin{array}{c}-0.0828^{* * *} \\
(0.0130) \\
\end{array}$ & $\begin{array}{c}-0.0968^{* * *} \\
(0.0255) \\
\end{array}$ \\
\hline JetBlue $^{\dagger \pm}$ & $\begin{array}{c}-0.0525^{* * *} \\
(0.131)\end{array}$ & $\begin{array}{c}-0.0485^{* *} \\
(0.0210)\end{array}$ \\
\hline
\end{tabular}


${ }^{ \pm}$EDLP carriers

\section{Appendix B: A Primer on Airline Classifications}

There is an abundance of terms when it comes to classifying U.S. Domestic carriers - airlines are frequently referred to as legacy carriers, regional carriers, low-cost airlines, etc. While many of these terms including no-frills, discount, budget, etc., are loosely used in the popular press/media, there are more concrete origins for some of these terms. We can broadly see three primary bases for classifications, operating business model based, revenue based and pricing based. The first two have their origins in the Bureau of Transportation Statistics (BTS) publications of the U.S. Department of Transportation (DOT), while the third is more recent (Chellappa et al. 2011).

\section{Operating business model-based}

As a high fixed-cost industry, initial categorizations are largely based on geographical scope of operations and the type of underlying operational infrastructure. $\mathrm{DOT}^{11}$ says that there are "three carrier groupings: network, low cost, and regional. Network carriers use a traditional hub-and-spoke system for scheduling flights. Low-cost carriers operate under a generally recognized low-cost business model, which may include a single passenger class of service, standardized aircraft utilization, limited in-flight services, use of smaller and less expensive airports, and lower employee wages and benefits. Regional carriers provide service from small cities and primarily use smaller jets. Regional carriers are also used to support larger network carrier traffic into and out of smaller airports to the network carriers' hub airports."

As of 2004, BTS classified the seven airlines Alaska Airlines, American Airlines, Continental, Delta, Northwest, United, and US Airways as network carriers and the following seven airlines, AirTran, America West, ATA, Frontier, JetBlue, Southwest, and Spirit as lowcost carriers. It is important to note that while the general belief is that the low-cost carriers

\footnotetext{
${ }^{11}$ Available at:
}

http://www.bts.gov/publications/journal_of_transportation_and_statistics/volume_08_number_01/ht $\underline{\mathrm{ml} / \text { data_review/index.html }}$ 
charge relatively low prices, the term itself has its origin in operating costs. For example, Table B1 shows the differences in aircraft types, equipment size, and cost per available-seat-mile (CASM) - all of which are infrastructural elements that differentiate low-cost carriers from network carriers. Operating and maintaining a small variety of airplanes has been reported as an important cost-saving measure (Neels 2000). Readers will note that the low-cost carriers have uniformly low CASM, low variance in aircraft types and plane sizes.

Table B1: Summary Statistics on Selected Operational Details (as of third quarter, 2004)

\begin{tabular}{|c|c|c|c|c|c|c|c|}
\hline \multirow[t]{2}{*}{$\begin{array}{l}\text { Airline Name } \\
\text { (ID)* }\end{array}$} & \multicolumn{2}{|c|}{$\begin{array}{c}\text { (Number of) } \\
\text { Types of Aircraft } \\
\text { Operated }^{12}\end{array}$} & \multicolumn{2}{|c|}{ Equipment Size } & \multicolumn{2}{|c|}{ Load Factor } & \multirow[t]{2}{*}{ CASM } \\
\hline & Mean & S.D. & Mean & S.D. & Mean & S.D. & \\
\hline American (AA) & 1.86 & 1.07 & 141.98 & 15.73 & 0.74 & 0.08 & 10.93 \\
\hline Alaska (AS) & 1.50 & 0.55 & 138.31 & 5.31 & 0.78 & 0.03 & 10.05 \\
\hline JetBlue $^{\dagger}$ (B6) & 1.00 & 0.00 & 158.99 & 3.77 & 0.83 & 0.05 & 6.13 \\
\hline Continental (CO) & 4.22 & 2.35 & 134.85 & 11.68 & 0.78 & 0.06 & 11.02 \\
\hline Delta (DL) & 2.32 & 1.66 & 167.93 & 13.84 & 0.65 & 0.08 & 13.94 \\
\hline Frontier $^{\dagger}$ (F9) & 1.91 & 0.94 & 130.31 & 2.37 & 0.60 & 0.08 & 9.47 \\
\hline $\operatorname{AirTran}^{\dagger}(\mathrm{FL})$ & 1.05 & 0.22 & 117.30 & 0.38 & 0.70 & 0.02 & 8.62 \\
\hline America West ${ }^{\dagger}(\mathrm{HP})$ & 1.20 & 0.64 & 139.64 & 4.59 & 0.85 & 0.03 & 8.46 \\
\hline Spirit $^{\dagger}(\mathrm{NK})$ & 1.00 & 0.00 & 148.96 & 0.46 & 0.80 & 0.04 & 8.60 \\
\hline Northwest (NW) & 3.46 & 2.18 & 130.70 & 8.45 & 0.65 & 0.05 & 13.91 \\
\hline $\mathrm{ATA}^{\dagger}(\mathrm{TZ})$ & 2.10 & 0.82 & 185.77 & 5.74 & 0.73 & 0.04 & 7.26 \\
\hline United (UA) & 3.54 & 1.85 & 138.83 & 11.27 & 0.79 & 0.04 & 12.25 \\
\hline US Airways (US) & 2.70 & 1.74 & 126.86 & 6.25 & 0.60 & 0.08 & 16.13 \\
\hline Southwest $^{\dagger}(\mathrm{WN})$ & 1.00 & 0.00 & 134.36 & 3.63 & 0.66 & 0.11 & 7.60 \\
\hline
\end{tabular}

${ }^{12}$ Different sub-models or configurations under the same model (e.g. Boeing 737-400 and Boeing 737-500) are considered as the same type of aircraft. 


\section{Revenue-based}

This is also a DOT classification and it consists of "three major categories: majors, nationals, and regionals. Major carriers have annual operating revenues above $\$ 1$ billion, national carriers have operating revenues between $\$ 100$ million and $\$ 1$ billion, and regional carriers have operating revenues less than $\$ 100$ million."

Also, note that in this classification, the "regional category may not include the same carriers under the revenue size definition and the business model definition," and the term commuter airlines have often been used in place of regional airlines. While there were more than 140 such airlines in nineties, the top 50 is said to account for more than $97 \%$ of this group's revenue $^{13}$

By this schema, today there are 4 major airlines: American Airlines, Delta and United being the strongest and Southwest Airlines (previously a national airline), being the new addition to this category. Also, note that the term "national" here does not refer to any geographic boundaries.

\section{Pricing-based}

Literature in marketing first identified Southwest Airlines as practicing the EDLP format of pricing (Hoch, Dreze et al. 1994). More recently Chellappa, et al., (2011) identified this heterogeneity in price-format as both an important source of differentiation amongst the US domestic carriers and a source of dispersion of prices in the market. As of 2004, Southwest and JetBlue not only actively advertised their practice of Everyday Low Price (EDLP) price-format (see Exhibits 1 and 2) but also exhibited prices that are distinctly more consistent than all other airlines, including the so-called low-cost carriers. We can see from Table B2 that the weekly price-consistency of Southwest and JetBlue to be higher (low value for the weighted Coefficient of Variance measure) than all carriers and significantly higher than network carriers.

Table B2: Route-adjusted Price Statistics by Airline

\begin{tabular}{|l|c|c|}
\hline \multirow{2}{*}{ Airline Name (ID) } & \multicolumn{2}{|c|}{ Price } \\
\cline { 2 - 3 } & Mean & Weighted C.V. \\
\hline
\end{tabular}

\footnotetext{
${ }^{13}$ Please see http://business.highbeam.com/industry-reports/transportation/air-transportation-scheduled
} 


\begin{tabular}{|c|c|c|}
\hline American (AA) & 354.11 & 0.39 \\
\hline Alaska (AS) & 490.50 & 6.94 \\
\hline JetBlue $^{\dagger}(\mathrm{B} 6)$ & 205.59 & 0.01 \\
\hline Continental $(\mathrm{CO})$ & 383.98 & 0.42 \\
\hline Delta (DL) & 282.39 & 0.40 \\
\hline Frontier $^{\dagger}(\mathrm{F} 9)$ & 293.92 & 0.18 \\
\hline $\operatorname{AirTran}^{\dagger}(\mathrm{FL})$ & 219.80 & 0.02 \\
\hline America West ${ }^{\dagger}(\mathrm{HP})$ & 334.89 & 0.03 \\
\hline Spirit $^{\dagger}$ (NK) & 186.54 & 0.02 \\
\hline Northwest (NW) & 373.78 & 0.18 \\
\hline $\mathrm{ATA}^{\dagger}(\mathrm{TZ})$ & 195.05 & 0.07 \\
\hline United (UA) & 343.63 & 0.63 \\
\hline US Airways (US) & 371.55 & 4.87 \\
\hline Southwest $^{\dagger}(\mathrm{WN})$ & 161.51 & 0.01 \\
\hline
\end{tabular}

The ability to create, manage and change prices (components of economic menu costs) has been greatly advanced with innovations and improvements in information technology. At one end, it allows airlines to set prices by executing complex yield/revenue management algorithms which allows firms to manage complex promotions, discounts and deals (called a PROMO or HILO strategy in marketing) efficiently. On other hand, those that undertake a more consistent approach to pricing prefer not be subject to price comparisons easily. These airlines have employed technology and the Internet to directly reach their clientele typically eschewing both online and offline travel agents.

Non-EDLP airlines sell their tickets through their own and Online Travel Agent's (Orbitz, Expedia, etc.) Web sites, the EDLP carriers sold tickets directly online only through their own Web site (JetBlue has recently decided to offer some of its tickets through OTAs as well). Currently over 26 percent of all tickets are purchased online (expected to exceed $41 \%$ by $2012^{14}$ ) including those through OTAs, however the number for an EDLP carrier like Southwest is staggering. Southwest's own Web site (http://www.southwest.com/) accounts for over $75 \%$ of its tickets purchased while an airline like Delta sells less than half this volume online (which includes its own Web site and OTAs).

Note that more recently AirTran and Frontier also use the language "everyday low fares" as do some international airlines including Malysian Airlines and United Airlines Canada.

${ }^{14}$ According to the Airline IT Trends Survey 2009 by SITA. Available at: www.sita.aero/content/airlineit-trends-survey-2009 Last accessed on June 20, 2010. 
Although, the latter advertises these fares as "Take advantage of our everyday low fares while they last on united.ca.," the phrase "while they last" is more consistent with temporal promotions and somewhat contrarian to EDLP practice. In general caution should be exercised in the adoption on any airline classification and the terms always have to be placed in context.

Exhibit 1: Southwest Airlines - Advertising Message and Statement to Shareholders

\section{SOUTHWEST AIRLINES CO. $\not$, SIX STORIES OF FREEDOM}

\begin{tabular}{c}
\hline We give People the freedom to keep \\
fares low in every city we serve. These \\
are not merely introductory fares, they \\
are our everyday low fares - and they \\
are low by philosophy, not expediency." \\
Gary c. Kelly, cEo
\end{tabular}

"We, the People of Southwest Airlines, give our customers the freedom to fly. Every Customer is entitled to three simple rights: Low fares, lots of flights, and the friendliest service in the sky."

\section{— Elizabeth P. Sartain, Vice President — People}

Southwest Airlines stands for freedom and we are committed to providing our customers something different in the airline industry: everyday low fares and superior customer service. That philosophy served us well again in 1998, as we recorded our 26th consecutive year of profitability and our seventh consecutive record profit.

Earnings for 1998 were up 36 percent with a net profit margin of 10.4 percent and return on equity of 19.7 percent. This kind of financial performance is 
tops in our industry, as is our customer service. Very different for an airline. But then we are very different.

Exhibit 2: Jetblue Airways - Advertising Message and Corporation's SEC Filing

\section{Pricing}

Our low cost structure allows us to offer simplified, everyday low fares to our customers. We offer a range of fares, including 14-day, 7-day and 3-day advance purchase fares and a "walkup" fare in each of our markets. Our fares increase as the number of days prior to travel decreases, with our highest "walkup" fare generally at approximately twice the amount of our lowest 14-day advance purchase fare.

JetBlue Everyday Fares So you want to know how much it's going to cost you to fly in our comfy, leather seats. At JetBlue, we believe that a great airline experience doesn't have to cost you an arm and a leg. The fare ranges below are our everyday low prices and include fares with advance purchase restrictions. Seats are limited and may not be available on all flights. While we make every effort to keep these fares current, please visit the Buy Tickets section for the most accurate pricing and availability. 